\title{
Potential Energy Surface of Methanol Decomposition on $\mathrm{Cu}(110)$
}

\author{
Donghai Mei, ${ }^{*}, \dagger$ Lijun Xu, and Graeme Henkelman ${ }^{\ddagger}$ \\ Institute for Interfacial Catalysis, Pacific Northwest National Laboratory, Richland, Washington 99352, and \\ Department of Chemistry and Biochemistry, University of Texas at Austin, Austin, Texas 78712
}

Received: September 15, 2008; Revised Manuscript Received: January 13, 2009

\begin{abstract}
Combining the dimer saddle point searching method and periodic density functional theory calculations, the potential energy surface of methanol decomposition on $\mathrm{Cu}(110)$ has been mapped out. Each elementary step in the methanol decomposition reaction into $\mathrm{CO}$ and hydrogen occurs via one of three possible mechanisms: $\mathrm{O}-\mathrm{H}, \mathrm{C}-\mathrm{H}$, or $\mathrm{C}-\mathrm{O}$ bond scission. Multiple reaction pathways for each bond scission have been identified in the present work. Reaction pathway calculations are started from an initial (reactant) state with methanol adsorbed in the most stable geometry on $\mathrm{Cu}(110)$. The saddle point and corresponding final state of each reaction or diffusion mechanism were determined without assuming the reaction mechanism. In this way, the reaction paths are determined without chemical intuition. The harmonic pre-exponential factor of each identified reaction is calculated from a normal-mode analysis of the stationary points. Then, using harmonic transition state theory, the rate constant of each identified reaction pathway in the entire reaction network is obtained. The most favorable decomposition route for methanol on $\mathrm{Cu}(110)$ is found as follows: $\mathrm{CH}_{3} \mathrm{OH} \rightarrow \mathrm{CH}_{3} \mathrm{O} \rightarrow$ $\mathrm{CH}_{2} \mathrm{O}$. The rate-limiting step in this decomposition route is the dehydrogenation of methoxy to formaldehyde. Our calculations are in agreement with previous experimental observations and theoretical results.
\end{abstract}

\section{Introduction}

Understanding complex heterogeneous reactions on catalytic surfaces requires a detailed knowledge of how reaction intermediates interact with the surface and how the bond-breaking and the bond-making processes occur at the active site(s). Finding an accurate description of the spatiotemporal chemical transformation on the catalyst surface under practical reaction conditions is one of the biggest challenges in heterogeneous catalysis. Although state-of-the-art experimental surface science techniques can provide some valuable information on the atomic level, chemical intuition is still needed to propose a reaction mechanism describing the reaction progress and to elucidate experimental observations. In this respect, theoretical studies based upon density functional theory (DFT) calculations have proven useful to complement experimental measurements of reaction products and rates. The mechanism of a heterogeneous catalytic reaction generally consists of a series of elementary steps including the adsorption of reactants, surface reactions (bond-making or bond-breaking), diffusion of surface intermediates, and desorption of products. In order to obtain the thermochemistry and the kinetics of each elementary step from DFT calculations, an initial and final state, and a reaction pathway between them is typically assumed. Then a minimum energy pathway can be optimized locally to identify a transition state along this pathway. An overall reaction path can be obtained from the calculated activation barrier of each elementary step. This approach becomes challenging if there are (as there usually are) different reaction pathways for each elementary step. Calculating one pathway for each elementary step is not necessarily enough to illustrate the complex potential energy surface for reactions on the catalyst surface. Furthermore, the states along an assumed reaction path might not include those

\footnotetext{
* Corresponding author. E-mail: donghai.mei@pnl.gov.

${ }^{\dagger}$ Pacific Northwest National Laboratory.

¥ University of Texas at Austin.
}

where the bond-breaking or bond-making processes actually occur. Here, we present a methodology that overcomes some of these limitations. Our approach assumes an initial state from which dimer saddle point searches are used to identify (sometimes many) possible reaction mechanisms ${ }^{1-4}$ and subsequent intermediate states. Repeating this process, we build a network of states from which the most favorable overall reaction pathway can be determined. We show that this procedure can be used to determine the potential energy surface for the decomposition of methanol on $\mathrm{Cu}(110)$ without assuming the reaction mechanism.

Recently, Cu-based catalysts have attracted a great deal of attention for methanol decomposition and synthesis as a possible source of energy for the hydrogen economy. ${ }^{5,6}$ Methanol, which is commercially produced from syngas using $\mathrm{Cu} / \mathrm{ZnO} / \mathrm{Al}_{2} \mathrm{O}_{3}$ catalysts, can be used as the feedstock in direct methanol fuel cells. Steam reforming of methanol on this catalyst has also proven to be an efficient way of producing large quantities of hydrogen. The pioneer experimental work of Wachs and Madix on methanol decomposition on $\mathrm{Cu}(110)$ suggested that the clean $\mathrm{Cu}(110)$ is not very active for methanol decomposition under UHV condition. ${ }^{7}$ Most of the preadsorbed methanol molecules desorb from the surface after heating. Only small amounts of formaldehyde desorb at $370 \mathrm{~K} .^{7,8} \mathrm{X}$-ray photoelectron spectroscopy (XPS) experiments indicated that methanol decomposes into methoxy on the clean $\mathrm{Cu}(110)$ surface at $270 \mathrm{~K} .{ }^{8}$ Experiments have also shown that two other low-index $\mathrm{Cu}$ surfaces, $\mathrm{Cu}(111)^{9}$ and $\mathrm{Cu}(100),{ }^{10}$ are inactive to methanol decomposition. With predosed oxygen atoms on the $\mathrm{Cu}(110)$ surface, methanol decomposition is significantly facilitated. Besides formaldehyde, other products were observed, such as water which desorbs at $250 \mathrm{~K}$ and hydrogen which desorbs at $470 \mathrm{~K}$. Sexton et al. reported similar observations of methanol reactions on $\mathrm{Cu}(110)$ using thermal desorption spectroscopy (TDS). ${ }^{11}$ The reaction mechanism of methanol decomposition is described as first involving $\mathrm{O}-\mathrm{H}$ bond scission to form methoxy followed by 
$\mathrm{C}-\mathrm{H}$ bond scission to form formaldehyde. Since formaldehyde binds weakly on the surface, formaldehyde desorbs from $\mathrm{Cu}(110)$ instead of further decomposition to $\mathrm{CO}$ and hydrogen $\left(\mathrm{H}_{2}\right)$.

Periodic slab DFT calculations have been performed to investigate methanol oxidation on the $\mathrm{Cu}(110)$ surface. $^{12-14}$ Sakong and Gross found that methanol and formaldehyde are weakly bound to this surface whereas methoxy is strongly bound. ${ }^{12}$ In their work, the dissociative adsorption of methanol, yielding surface methoxy and atomic hydrogen, was proposed as the first step in methanol decomposition. ${ }^{12}$ The reaction barrier for this step was calculated as $0.73 \mathrm{eV} .{ }^{12}$ Recently, these authors reported a similar activation barrier of $0.68 \mathrm{eV}$ for adsorbed methanol dissociation into methoxy. ${ }^{13}$ In agreement with experiments, this indicated methanol decomposition is unlikely on the clean $\mathrm{Cu}(110)$ surface because the energy for methanol desorption is only $0.34 \mathrm{eV}$. For the methoxy molecules which do react on the surface, the next step of decomposition leads to formaldehyde and atomic hydrogen with an activation barrier of $1.22 \mathrm{eV} .{ }^{13}$ The formate is weakly bound and will rapidly desorb into the gas phase. Comparing the barriers of these two steps, they concluded that the methoxy decomposition is the rate-limiting step in methanol decomposition on $\mathrm{Cu}(110) .^{12-14}$ Greeley and Mavrikakis calculated that methoxy decomposition into formaldehyde is also the rate-limiting step in methanol decomposition on $\mathrm{Cu}(111) .{ }^{15}$

In this work, we demonstrate a computational methodology based upon DFT and dimer method saddle point searches ${ }^{1-4}$ to identify catalytic reaction mechanisms. We use this method to map out the potential energy landscape of complete methanol decomposition on the clean $\mathrm{Cu}(110)$ surface. These calculations not only help us to identify other alternative reaction pathways for each elementary steps in the mechanism, which shed light on the complexity nature of methanol decomposition on $\mathrm{Cu}(110)$, but also provide a complete picture of the breaking or making of three common bonds $(\mathrm{O}-\mathrm{H}, \mathrm{C}-\mathrm{H}$, and $\mathrm{C}-\mathrm{O})$ of all reaction intermediates during methanol decomposition, which might be very useful to other relevant reactions. Furthermore, the calculated potential energy surface can also be used as reference energetic diagram for understanding how the preadsorbed oxygen atoms enhance methanol decomposition on $\mathrm{Cu}(110)$.

First, we give a brief description of the computational methodology. Then, starting from the initial state of adsorbed methanol, we identify multiple pathways for each elementary step along the methanol decomposition pathway to obtain a reaction network. Vibrational frequencies are calculated for each state to estimate entropic and quantum effects, and so that the reaction rate constants can be calculated using harmonic transition state theory. The rate-limiting step in methanol decomposition is then determined from our network of rate constants.

\section{Computational details}

Periodic plane-wave DFT calculations combined with minimum mode following saddle point searches using the dimer method were carried out to explore possible reaction and diffusion pathways in methanol decomposition on the $\mathrm{Cu}(110)$ surface. Ion-electron interactions were modeled with the use of ultrasoft pseudopotentials within the framework of the projector augmented wave method. ${ }^{16,17}$ The generalized gradient approximation with the Perdew-Wang 91 functional ${ }^{18}$ was used to model electron correlation. The geometry of all stationary points were found with the conjugate-gradient algorithm, and considered converged when the force on each ion dropped below $0.001 \mathrm{eV} / \AA$. The $\mathrm{Cu}(110)-2 \times 2$ surface was modeled with a supercell containing a slab of six atomic layers. Periodic images of the slab were separated by a $10 \AA$ vacuum gap. The bottom four layers were held frozen at equilibrium bulk positions; all other atoms were fully relaxed in our optimizations. Several surface sizes, numbers of atomic layers, and $k$-point sampling meshes were used to test for convergence. A $2 \times 2 \times 1$ Monkhorst-Pack $k$-point mesh and a $p(2 \times 3)$ surface were found to result in relative energies converged to within $0.1 \mathrm{eV}$. All calculations were performed using the Vienna ab initio simulation package (VASP). ${ }^{19,20}$

Binding energies of adsorbates on the surface, $E_{\mathrm{b}}$, were calculated as

$$
E_{\mathrm{b}}=E_{\text {adsorbate }+\mathrm{Cu}(110)}-\left(E_{\text {adsorbate }}+E_{\mathrm{Cu}(110)}\right)
$$

where $E_{\text {adsorbate }+\mathrm{Cu}(110)}$ is the energy of the adsorbate molecule interacting with the $\mathrm{Cu}(110)$ slab, $E_{\mathrm{Cu}(110)}$ is the total energy of bare $\mathrm{Cu}(110)$ slab, and $E_{\text {adsorbate }}$ is the energy of the gas phase adsorbate molecule.

To find reaction pathways, minimum-mode following searches were used to climb up the potential surface from minima to saddle points. Searches were initiated from stable minima by making a random displacement of the adsorbed molecule(s). From this initial point the dimer method was used to find the lowest curvature mode and follow it to a saddle. ${ }^{1,3}$ Each successful search was followed up with a finite-difference normal-mode calculation to verify that a first-order saddle was found and to evaluate the prefactor of the reaction mechanism. The minimum-energy path from each saddle was followed by minimization to determine the initial and final state of the reaction. Additional details of this calculation procedure are included in recent publications. ${ }^{1-4}$

\section{Results}

3.1. Determination of Initial States. In the present study only the initial state, i.e., the stable methanol adsorption state was used to initiate our exploration of the reaction and diffusion pathways of methanol decomposition. The initial state of each subsequent reaction intermediate is chosen by optimizing the final state of the previous dehydrogenation step, with the coadsorbed atomic hydrogen removed. The reaction intermediates are not required to be in their most stable configurations; they may be kinetic intermediates. The most stable configuration of each surface intermediate is determined by comparing all the configurations identified in our searching processes. Table 1 and Figure 1 list the states of each reaction intermediate used in the exploration of reaction pathways. Other stable adsorption configurations of reaction intermediates that were identified in our search are given in Table 2 and Figure 2.

3.2. Reaction Pathways. 3.2.1. Methanol $\left(\mathrm{CH}_{3} \mathrm{OH}\right) \mathrm{De}$ composition. In the first step, we put one $\mathrm{CH}_{3} \mathrm{OH}$ molecule at the top site on $\mathrm{Cu}(110)$. As shown in Figure 1a, $\mathrm{CH}_{3} \mathrm{OH}$ binds with the uppermost $\mathrm{Cu}$ atom through the $\mathrm{O}$ atom, which is in agreement with previous experiments. ${ }^{8}$ The $\mathrm{O}-\mathrm{Cu}$ bond is tilted at $18^{\circ}$ to the surface normal, and has a length of $2.09 \AA$, which is slightly shorter than the reported value of $2.16 \AA .{ }^{13}$ The calculated binding energy of $\mathrm{CH}_{3} \mathrm{OH}$ at the top site is -0.55 $\mathrm{eV}$. This is somewhat weaker than the experimental estimation of $-0.70 \mathrm{eV}$ from first-order temperature-programmed desorption (TPD), ${ }^{7}$ but stronger than the previous DFT calculation results of -0.41 and $-0.34 \mathrm{eV}$ using different functionals. ${ }^{12,13}$ 

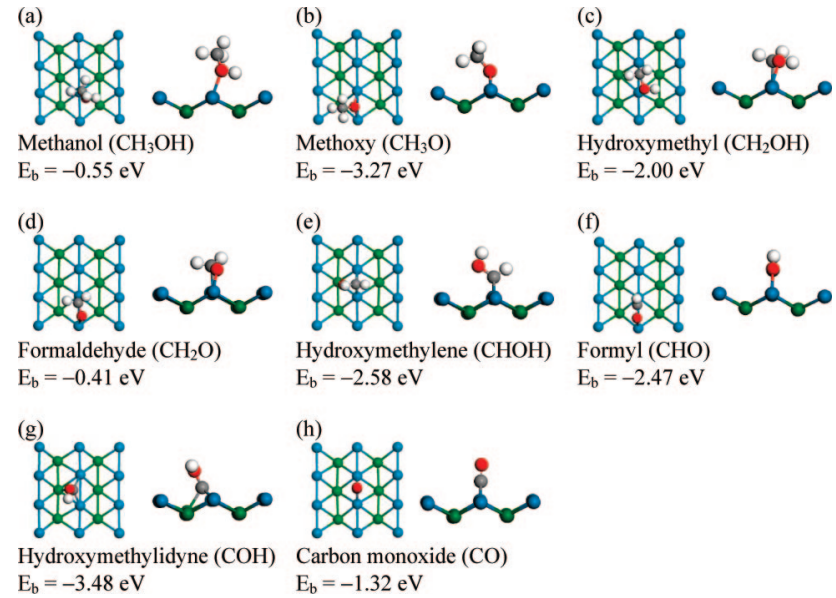

Figure 1. Starting configurations of reaction intermediates used to search for reaction pathways of methanol decomposition on $\mathrm{Cu}(110)$. The $\mathrm{C}, \mathrm{O}$, and $\mathrm{H}$ atoms are gray, red, and white, respectively. The uppermost layer of $\mathrm{Cu}$ atoms are blue and the second are green.

3.2.1.1. $\mathrm{O}-\mathrm{H}$ Scission. The $\mathrm{O}-\mathrm{H}$ bond scission in $\mathrm{CH}_{3} \mathrm{OH}$ yields methoxy $\left(\mathrm{CH}_{3} \mathrm{O}\right)$ and atomic $\mathrm{H}$. Starting with the adsorbed $\mathrm{CH}_{3} \mathrm{OH}$ at the top site, three reaction pathways involving $\mathrm{O}-\mathrm{H}$ bond scission of $\mathrm{CH}_{3} \mathrm{OH}$ have been identified. As shown in Figure $3 \mathrm{a}, \mathrm{CH}_{3} \mathrm{OH}$ tilts toward the trough in the [001] direction in Path $\mathrm{I}$. As the $\mathrm{O}-\mathrm{H}$ bond breaks, the $\mathrm{CH}_{3} \mathrm{O}$ fragment remains binding at the top site and the dissociated atomic $\mathrm{H}$ moves to the short-bridge site on the adjacent $\mathrm{Cu}$ row. The distance between the $\mathrm{O}$ atom of $\mathrm{CH}_{3} \mathrm{O}$ and atomic $\mathrm{H}$ is elongated to $1.56 \AA$. After the transition state, $\mathrm{CH}_{3} \mathrm{O}$ and atomic $\mathrm{H}$ move further away from each other. The activation barrier of Path $\mathrm{I}$ is $0.86 \mathrm{eV}$, and the reaction energy is $+0.33 \mathrm{eV}$. In the second path, the $\mathrm{O}-\mathrm{H}$ bond breaks along the [1ㅣㅣㄹ direction. $\mathrm{CH}_{3} \mathrm{O}$ still stays at the top site while the $\mathrm{O}-\mathrm{H}$ bond is elongated by moving the hydroxyl $\mathrm{H}$ atom to the adjacent pseudo-fcc(111) site. At the final state, $\mathrm{CH}_{3} \mathrm{O}$ binds at the short-bridge and atomic $\mathrm{H}$ binds at the pseudo-fcc(111) site. The activation barrier for Path II is $1.10 \mathrm{eV}$. The Path II of $\mathrm{O}-\mathrm{H}$ bond scission is exothermic, with the reaction energy of $-0.19 \mathrm{eV}$. The third path (Path III) involving $\mathrm{O}-\mathrm{H}$ bond scission in $\mathrm{CH}_{3} \mathrm{OH}$ is similar to the Path II. Instead of binding at the pseudo-fcc(111) site, the atomic $\mathrm{H}$ binds at the adjacent short-bridge site at the final state of Path III. The resulting activation barrier is 0.07 $\mathrm{eV}$ higher than that of Path II. A fourth path (Path IV) was found in which the $\mathrm{CH}_{3} \mathrm{OH}$ first diffuses from the top site to the short-bridge site, at which the binding energy is only 0.05 $\mathrm{eV}$ higher than at the top site. From the short-bridge site, the $\mathrm{O}-\mathrm{H}$ bond breaking of $\mathrm{CH}_{3} \mathrm{OH}$ is very similar to the Path $\mathrm{I}$. However, we find that the activation barrier of Path IV is 0.63 $\mathrm{eV}$, which is lower than the barrier of $0.86 \mathrm{eV}$ for Path $\mathrm{I}$. Furthermore, we note that Path IV is exothermic $(-0.24 \mathrm{eV})$ while Path I is endothermic $(+0.33 \mathrm{eV})$. This can be attributed the different configurations of coadsorbed $\mathrm{CH}_{3} \mathrm{O}$ in the final states of Path I and IV (top vs the short-bridge site respectively).

Comparing the barriers of the four pathways, it is clear that Path IV is favorable for $\mathrm{O}-\mathrm{H}$ bond scission of $\mathrm{CH}_{3} \mathrm{OH}$ on $\mathrm{Cu}(110)$. We also note that the transition states of all four $\mathrm{O}-\mathrm{H}$ bond scission pathways are "early" transition states in that the configurations of the transition states are close to the initial states. The distance between the $\mathrm{O}$ atom of $\mathrm{CH}_{3} \mathrm{O}$ and the dissociating $\mathrm{H}$ atom is related to the activation barrier; the longer the distance at the transition state, the higher the activation barrier.
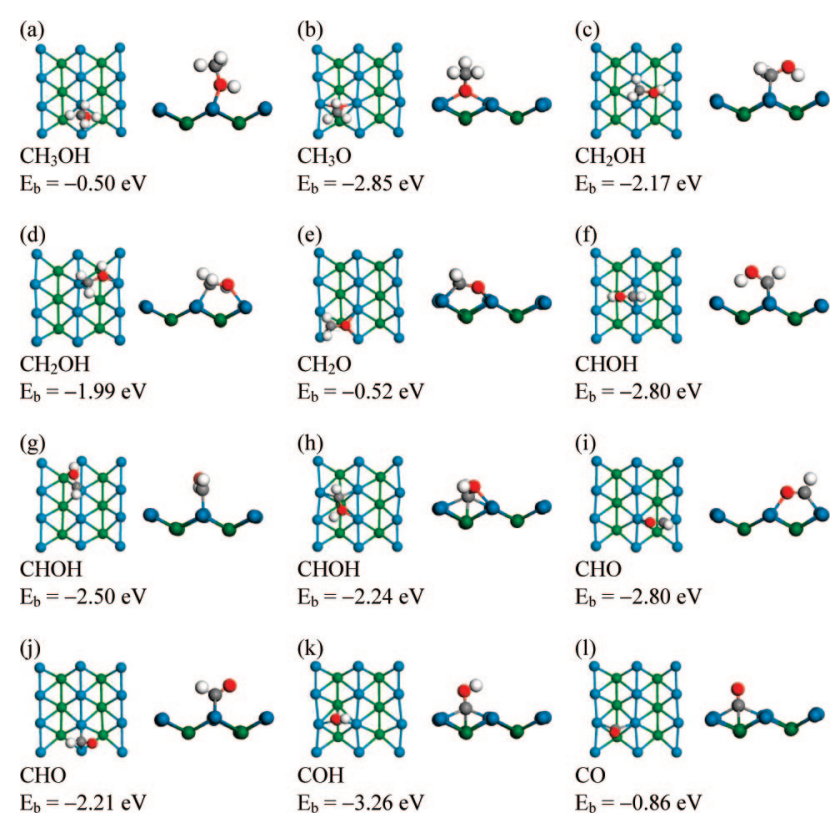

Figure 2. Stable configurations of reaction intermediates identified in the searching process. The color scheme is the same as in Figure 1.

3.2.1.2. $\mathrm{C}-\mathrm{H}$ Scission. $\mathrm{C}-\mathrm{H}$ bond scission in $\mathrm{CH}_{3} \mathrm{OH}$ produces hydroxymethyl $\left(\mathrm{CH}_{2} \mathrm{OH}\right)$ and atomic $\mathrm{H}$. Only one such pathway, shown in Figure $3 \mathrm{~b}$, was found. The $\mathrm{C}-\mathrm{H}$ bond in $\mathrm{CH}_{3} \mathrm{OH}$ is $1.10 \AA$ at the initial state. The $\mathrm{C}-\mathrm{H}$ bond scission begins with the rotation of $\mathrm{CH}_{3} \mathrm{OH}$, resulting in hydroxyl group $(\mathrm{OH})$ of $\mathrm{CH}_{3} \mathrm{OH}$ moving along the [001] direction to the trough and simultaneously the methyl group $\left(\mathrm{CH}_{3}\right)$ moving down to the surface. At the transition state, $\mathrm{CH}_{2} \mathrm{OH}$ binds at the top site through the $\mathrm{C}$ atom and atomic $\mathrm{H}$ binds the adjacent short-bridge site. The broken $\mathrm{C}-\mathrm{H}$ bond length is $1.87 \AA$. In the final state, the $\mathrm{C}$-bound $\mathrm{CH}_{2} \mathrm{OH}$ moves to the short-bridge site. The distance between the $\mathrm{C}$ atom of $\mathrm{CH}_{2} \mathrm{OH}$ and the $\mathrm{H}$ atom increases to $2.95 \AA$. The activation barrier for the $\mathrm{C}-\mathrm{H}$ bond scission of $\mathrm{CH}_{3} \mathrm{OH}$ is $1.34 \mathrm{eV}$. The reaction pathway is endothermic with a reaction energy of $+0.74 \mathrm{eV}$.

3.2.1.3. $C-O$ Scission. Two possible pathways for $\mathrm{C}-\mathrm{O}$ bond scission of $\mathrm{CH}_{3} \mathrm{OH}$ yielding $\mathrm{CH}_{3}$ and $\mathrm{OH}$ have been found. As shown in Figure $3 \mathrm{~b}, \mathrm{OH}$ moves along the [1 $1 \overline{10}]$ direction to the neighboring short-bridge site and $\mathrm{CH}_{3}$ moves down to the surface as the $\mathrm{C}-\mathrm{O}$ bond breaks. At the final state of Path I, the O-bound $\mathrm{OH}$ binds at the pseudo-fcc(111) site and $\mathrm{C}$-bound $\mathrm{CH}_{3}$ group binds at the short-bridge site. The activation barrier for Path $\mathrm{I}$ is $1.47 \mathrm{eV}$ and the reaction energy is $-0.46 \mathrm{eV}$. The second path of $\mathrm{C}-\mathrm{O}$ bond scission in $\mathrm{CH}_{3} \mathrm{OH}$ (Path II) begins with $\mathrm{OH}$ moving toward along the [001] direction to the trough. At the transition state, $\mathrm{OH}$ binds at the long-bridge site through the $\mathrm{O}$ atom. Then $\mathrm{OH}$ continues to move away from $\mathrm{CH}_{3}$ group. In the final state, the $\mathrm{CH}_{3}$ group binds at the short-bridge site and $\mathrm{OH}$ binds at the short-bridge site on the adjacent $\mathrm{Cu}$ row. The barrier of Path II is $1.74 \mathrm{eV}$, which is higher than Path I.

The first step of $\mathrm{CH}_{3} \mathrm{OH}$ decomposition is achieved by breaking one of three bonds $(\mathrm{O}-\mathrm{H}, \mathrm{C}-\mathrm{H}$ or $\mathrm{C}-\mathrm{O})$. Multiple pathways for each bond scission are identified. In agreement with experimental evidence that only $\mathrm{CH}_{3} \mathrm{O}$ was observed on $\mathrm{Cu}(110),{ }^{7,8,11}$ our results show that the $\mathrm{O}-\mathrm{H}$ bond scission leading to $\mathrm{CH}_{3} \mathrm{O}$ and atomic $\mathrm{H}$ is favored.

3.2.2. Methoxy $\left(\mathrm{CH}_{3} \mathrm{O}\right)$ Decomposition. $\mathrm{CH}_{3} \mathrm{O}$ has been well-characterized experimentally as a reaction intermediate in methanol decomposition on the $\mathrm{Cu}(110)$ surface. ${ }^{7,8,11}$ Ultraviolet photoelectron spectroscopy (UPS) experiments show that $\mathrm{CH}_{3} \mathrm{O}$ 
TABLE 1: Geometric and Energetic Parameters of Reaction Intermediates Used To Search for Possible Reaction Pathways

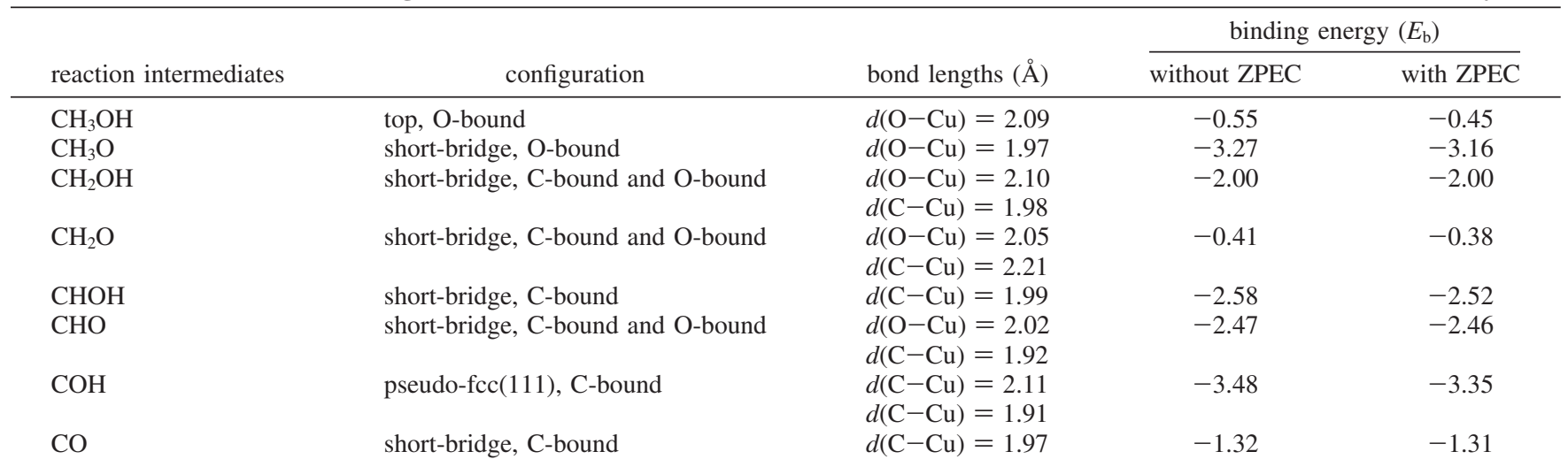

TABLE 2: Geometric and Energetic Parameters of Reaction Intermediates as Identified Stable States

\begin{tabular}{lllr}
\hline reaction intermediates & configuration & bond lengths $(\AA)$ & binding energy $\left(E_{\mathrm{b}}\right)$ without ZPEC \\
\hline $\mathrm{CH}_{3} \mathrm{OH}$ & short-bridge, O-bound & $d(\mathrm{O}-\mathrm{Cu})=2.21$ & -0.50 \\
& & $d(\mathrm{O}-\mathrm{Cu})=2.46$ & -2.85 \\
$\mathrm{CH}_{3} \mathrm{O}$ & long-bridge, O-bound & $d(\mathrm{O}-\mathrm{Cu})=2.07$ & -2.17 \\
$\mathrm{CH}_{2} \mathrm{OH}$ & short-bridge, C-bound & $d(\mathrm{C}-\mathrm{Cu})=2.10$ & -1.99 \\
& long-bridge, C-bound and O-bound & $d(\mathrm{O}-\mathrm{Cu})=2.04$ & -0.52 \\
& & $d(\mathrm{C}-\mathrm{Cu})=2.19$ & $d(\mathrm{O}-\mathrm{Cu})=2.05$ \\
$\mathrm{CH}_{2} \mathrm{O}$ & long-bridge, C-bound and O-bound & $d(\mathrm{C}-\mathrm{Cu})=2.21$ & -2.80 \\
& & $d(\mathrm{C}-\mathrm{Cu})=2.00$ & -2.50 \\
$\mathrm{CHOH}$ & short-bridge, C-bound & $d(\mathrm{C}-\mathrm{Cu})=2.00$ & -2.24 \\
& top, C-bound & $d(\mathrm{O}-\mathrm{Cu})=2.18$ & -2.80 \\
$\mathrm{CHO}$ & long-bridge, C-bound and O-bound & $d(\mathrm{C}-\mathrm{Cu})=2.04$ & -2.21 \\
& & $d(\mathrm{C}-\mathrm{Cu})=2.17$ & -3.01 \\
$\mathrm{COH}$ & long-bridge, C-bound and O-bound & $d(\mathrm{O}-\mathrm{Cu})=2.01$ & -3.26 \\
$\mathrm{CO}$ & & $d(\mathrm{C}-\mathrm{Cu})=1.92$ & -0.86
\end{tabular}

adsorbs on $\mathrm{Cu}(110)$ through the $\mathrm{O}$ atom with an off-normal orientation. ${ }^{8,11}$ In agreement with experiments, our calculation show that $\mathrm{CH}_{3} \mathrm{O}$ binds at the short-bridge site through the $\mathrm{O}$ atom. As shown in Figure $1 \mathrm{~b}$, the $\mathrm{C}-\mathrm{O}$ axis of $\mathrm{CH}_{3} \mathrm{O}$ tilts in the [001] and the [110] direction by $13^{\circ}$ and $33^{\circ}$, respectively. This is not quite consistent with previous Near Edge X-ray Absorption Fine Structure (NEXAFS) result that the $\mathrm{C}-\mathrm{O}$ axis is tilted by $36^{\circ} \pm 5^{\circ}$ in both azimuths. ${ }^{21}$ The binding energy of $\mathrm{CH}_{3} \mathrm{O}$ at the short-bridge site is $-3.27 \mathrm{eV}$, slightly stronger than previously reported DFT value of $-2.98 \mathrm{eV} .^{13}$ The $\mathrm{O}-\mathrm{Cu}$ bond length of adsorbed $\mathrm{CH}_{3} \mathrm{O}$ at the short-bridge site is 1.97 $\AA$, in good agreement with the result of $1.96 \AA .{ }^{13}$ The possible reaction pathways for $\mathrm{CH}_{3} \mathrm{O}$ decomposition are either via $\mathrm{C}-\mathrm{H}$ bond scission or $\mathrm{C}-\mathrm{O}$ bond scission. The initial state used for searching is $\mathrm{CH}_{3} \mathrm{O}$ binding at the short-bridge site.

3.2.2.1. $\mathrm{C}-\mathrm{H}$ Scission. Breaking the $\mathrm{C}-\mathrm{H}$ bond in $\mathrm{CH}_{3} \mathrm{O}$ leads to formaldehyde $\left(\mathrm{CH}_{2} \mathrm{O}\right)$ and atomic $\mathrm{H}$. When the $\mathrm{C}-\mathrm{H}$ bond breaks, one of methylic $\mathrm{H}$ atom of $\mathrm{CH}_{3}$ moves to the adjacent short-bridge site in the [1필 direction. The $\mathrm{C}-\mathrm{H}$ distance elongates from $1.11 \AA$ at the initial state to $1.73 \AA$ at the transition state. The activation barrier of the $\mathrm{C}-\mathrm{H}$ bond scission in $\mathrm{CH}_{3} \mathrm{O}$ is $1.11 \mathrm{eV}$. The reaction energy is $+1.01 \mathrm{eV}$, indicating this reaction pathway is highly endothermic. This also implies that the reverse pathway that $\mathrm{CH}_{2} \mathrm{O}$ recombines with atomic $\mathrm{H}$ to forming $\mathrm{CH}_{3} \mathrm{O}$ readily occurs. We also calculated the binding energies of atomic $\mathrm{H}$ on the $\mathrm{Cu}(110)$ surface. The binding energies of atomic $\mathrm{H}$ at the short-bridge and the pseudofcc(111) site are -2.41 and $-2.35 \mathrm{eV}$. Considering that the binding energy of $\mathrm{CH}_{2} \mathrm{O}$ at the short-bridge site is only -0.41
$\mathrm{eV}$, a strong repulsive interaction of $0.56 \mathrm{eV}$ between coadsorbed bridging $\mathrm{CH}_{2} \mathrm{O}$ and atomic $\mathrm{H}$ at the final state is found. Therefore, it is expected that the atomic $\mathrm{H}$ will quickly diffuse from the short-bridge site to the neighboring pseudo-fcc(111) site. Sakong and Gross reported a reaction pathway for the decomposition of $\mathrm{CH}_{3} \mathrm{O}$ via $\mathrm{C}-\mathrm{H}$ bond scission to produce $\mathrm{CH}_{2} \mathrm{O}$ in the gas phase and surface atomic $\mathrm{H}$ on the surface with an activation barrier between $1.22^{13}$ and $1.44 \mathrm{eV} .^{12,14}$ Furthermore, there is only a small barrier $(0.2 \mathrm{eV})$ for $\mathrm{CH}_{3} \mathrm{O}$ formation via gas-phase $\mathrm{CH}_{2} \mathrm{O}$ directly reacting with adsorbed $\mathrm{H}$ atom. ${ }^{12-14}$ Our calculations are consistent with the result of Sakong and Gross. ${ }^{12}$ Methoxy decomposition into formaldehyde by either reaction pathway is comparable due to the weak interaction between $\mathrm{CH}_{2} \mathrm{O}$ and $\mathrm{Cu}(110)$.

3.2.2.2. $\mathrm{C}-\mathrm{O}$ Scission. $\mathrm{CH}_{3} \mathrm{O}$ decomposition via $\mathrm{C}-\mathrm{O}$ bond scission yields $\mathrm{CH}_{3}$ and atomic $\mathrm{O}$. As shown in Figure 4, two reaction pathways (I and II) for $\mathrm{C}-\mathrm{O}$ bond scission in $\mathrm{CH}_{3} \mathrm{O}$ are found. The difference between these two pathways is the moving direction of $\mathrm{CH}_{3}$ as the $\mathrm{C}-\mathrm{O}$ bond ruptures. $\mathrm{CH}_{3}$ moves along the [1 10$]$ direction in Path I while moves along the [001] direction in Path II. We note that $\mathrm{CH}_{3}$ still binds at the top site through the $\mathrm{C}-\mathrm{Cu}$ bond in Path I at the transition state, while $\mathrm{CH}_{3}$ has been lifted off the surface in Path II. At the final state, $\mathrm{CH}_{3}$ binds at the short-bridge site and atomic $\mathrm{O}$ binds at the adjacent pseudo-fcc(111) site. Both Paths I and II are endothermic with the reaction energies of +0.32 and $+0.26 \mathrm{eV}$. The activation barriers of $\mathrm{C}-\mathrm{O}$ bond scission in Paths I and II are 1.67 and $2.10 \mathrm{eV}$, respectively, indicating that $\mathrm{C}-\mathrm{O}$ bond 
(a)

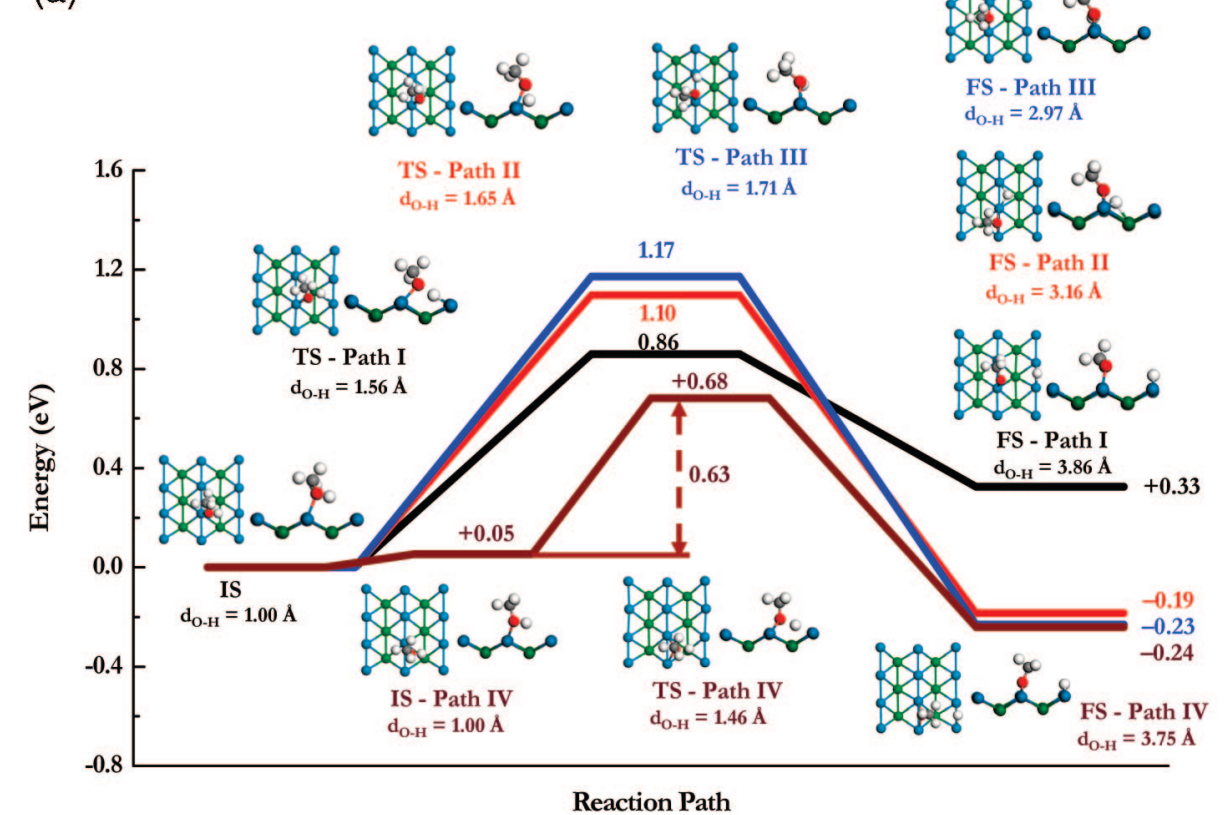

(b)
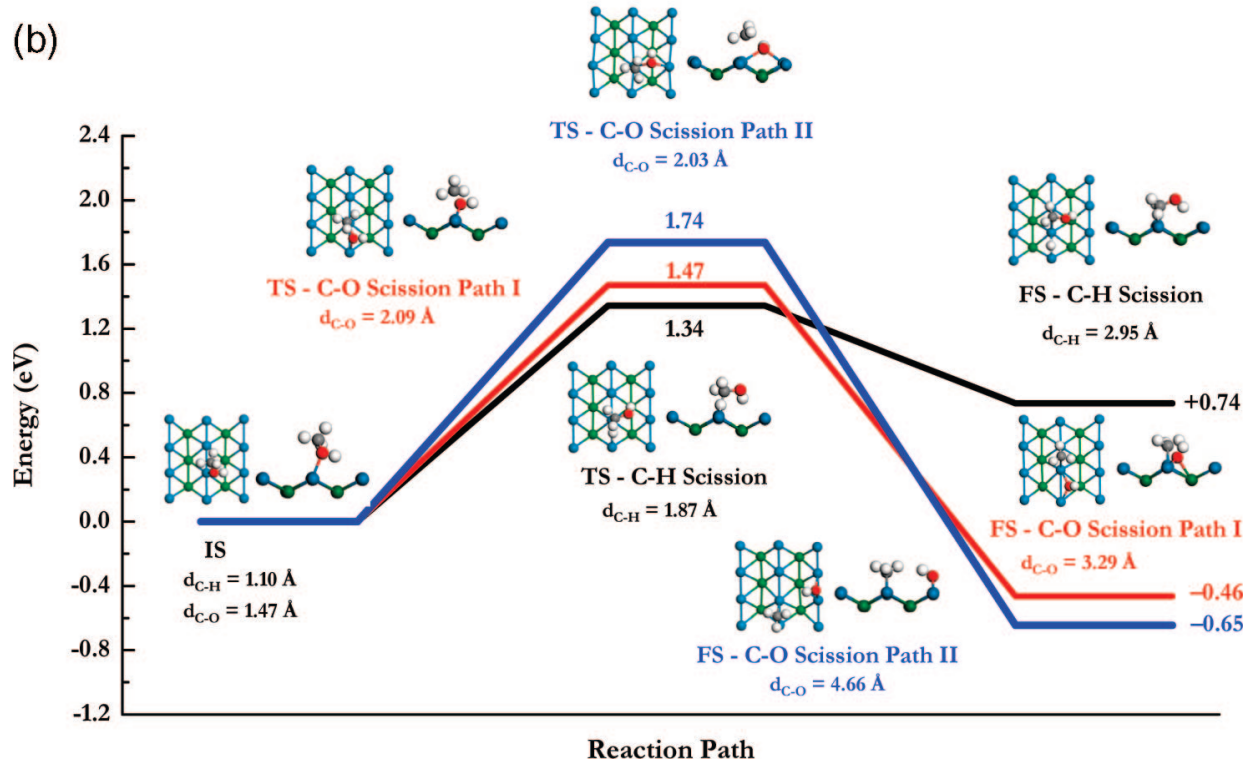

Figure 3. Reaction pathways of $\mathrm{CH}_{3} \mathrm{OH}$ : (a) $\mathrm{O}-\mathrm{H}$ scission; (b) $\mathrm{C}-\mathrm{H}$ and $\mathrm{C}-\mathrm{O}$ scission. IS: Initial State; TS: Transition State; FS: Final State.

scission of $\mathrm{CH}_{3} \mathrm{O}$ is unlikely. $\mathrm{C}-\mathrm{H}$ bond scission of $\mathrm{CH}_{3} \mathrm{O}$ yielding $\mathrm{CH}_{2} \mathrm{O}$ is the possible pathway for $\mathrm{CH}_{3} \mathrm{O}$ decomposition.

3.2.3. Hydroxymethyl $\left(\mathrm{CH}_{2} \mathrm{OH}\right)$ Decomposition. $\mathrm{CH}_{2} \mathrm{OH}$ is considered an important reaction intermediate in methanol decomposition on $\operatorname{Pt}(111)$ because of the competitive paths of $\mathrm{O}-\mathrm{H}$ and $\mathrm{C}-\mathrm{H}$ bond scission of $\mathrm{CH}_{3} \mathrm{OH}$ on $\mathrm{Pt}(111),{ }^{22-24}$ although it is not observed experimentally on $\mathrm{Pt}(111)$. As we discussed in section 3.2.1, the $\mathrm{O}-\mathrm{H}$ bond scission of $\mathrm{CH}_{3} \mathrm{OH}$ yielding $\mathrm{CH}_{3} \mathrm{O}$ is significantly more favorable than the $\mathrm{C}-\mathrm{H}$ bond scission of $\mathrm{CH}_{3} \mathrm{OH}$ yielding $\mathrm{CH}_{2} \mathrm{OH}$. In order to completely explore the reaction network of $\mathrm{CH}_{3} \mathrm{OH}$ decomposition on $\mathrm{Cu}(110)$, we study the decomposition of $\mathrm{CH}_{2} \mathrm{OH}$ because $\mathrm{CH}_{2} \mathrm{OH}$ might be connected with other reaction intermediates in $\mathrm{CH}_{3} \mathrm{OH}$ decomposition.

To the best of our knowledge, no theoretical study of $\mathrm{CH}_{2} \mathrm{OH}$ adsorption and decomposition on $\mathrm{Cu}(110)$ has been reported. One DFT calculation suggested that $\mathrm{CH}_{2} \mathrm{OH}$ adsorbed at the top site through the $\mathrm{C}$ atom on $\mathrm{Cu}(111) .{ }^{25} \mathrm{In}$ the present work, three adsorption configurations for $\mathrm{CH}_{2} \mathrm{OH}$ on $\mathrm{Cu}(110)$ are found. Among them $\mathrm{CH}_{2} \mathrm{OH}$ adsorbed at the short-bridge site through the $\mathrm{C}$ atom (Figure 2c) is found to be the most stable configuration. The binding energy of $\mathrm{CH}_{2} \mathrm{OH}$ at the short-bridge site is $-2.17 \mathrm{eV}$. $\mathrm{CH}_{2} \mathrm{OH}$ also binds at the short-bridge site with both $\mathrm{C}-\mathrm{Cu}$ and $\mathrm{O}-\mathrm{Cu}$ bonding (Figure 1c). This double bonding configuration of $\mathrm{CH}_{2} \mathrm{OH}$ at the short-bridge is slightly weaker (by $0.17 \mathrm{eV}$ ) than the single $\mathrm{C}-\mathrm{Cu}$ bonding configuration. The third configuration is that $\mathrm{CH}_{2} \mathrm{OH}$ binds at the longbridge site (Figure 2d). The binding energy of $\mathrm{CH}_{2} \mathrm{OH}$ at the long-bridge site is $-1.99 \mathrm{eV}$, which is the same as that at the short-bridge site with double bonds. For $\mathrm{CH}_{2} \mathrm{OH}$ decomposition, three bond scissions $(\mathrm{O}-\mathrm{H}, \mathrm{C}-\mathrm{H}$, and $\mathrm{C}-\mathrm{O})$ of $\mathrm{CH}_{2} \mathrm{OH}$ are possible. The adsorbed $\mathrm{CH}_{2} \mathrm{OH}$ at the short-bridge site with double bonds is used as the initial state for searching possible reaction paths.

3.2.3.1. $\mathrm{O}-\mathrm{H}$ Scission. The $\mathrm{O}-\mathrm{H}$ bond scission of $\mathrm{CH}_{2} \mathrm{OH}$ yields $\mathrm{CH}_{2} \mathrm{O}$ and the atomic $\mathrm{H}$. Four identified reaction pathways for $\mathrm{O}-\mathrm{H}$ bond scission are shown in Figure 5a and 5b. In Path $\mathrm{I}$, as the $\mathrm{O}-\mathrm{H}$ bond breaks, hydroxyl $\mathrm{H}$ moves along the [001] 


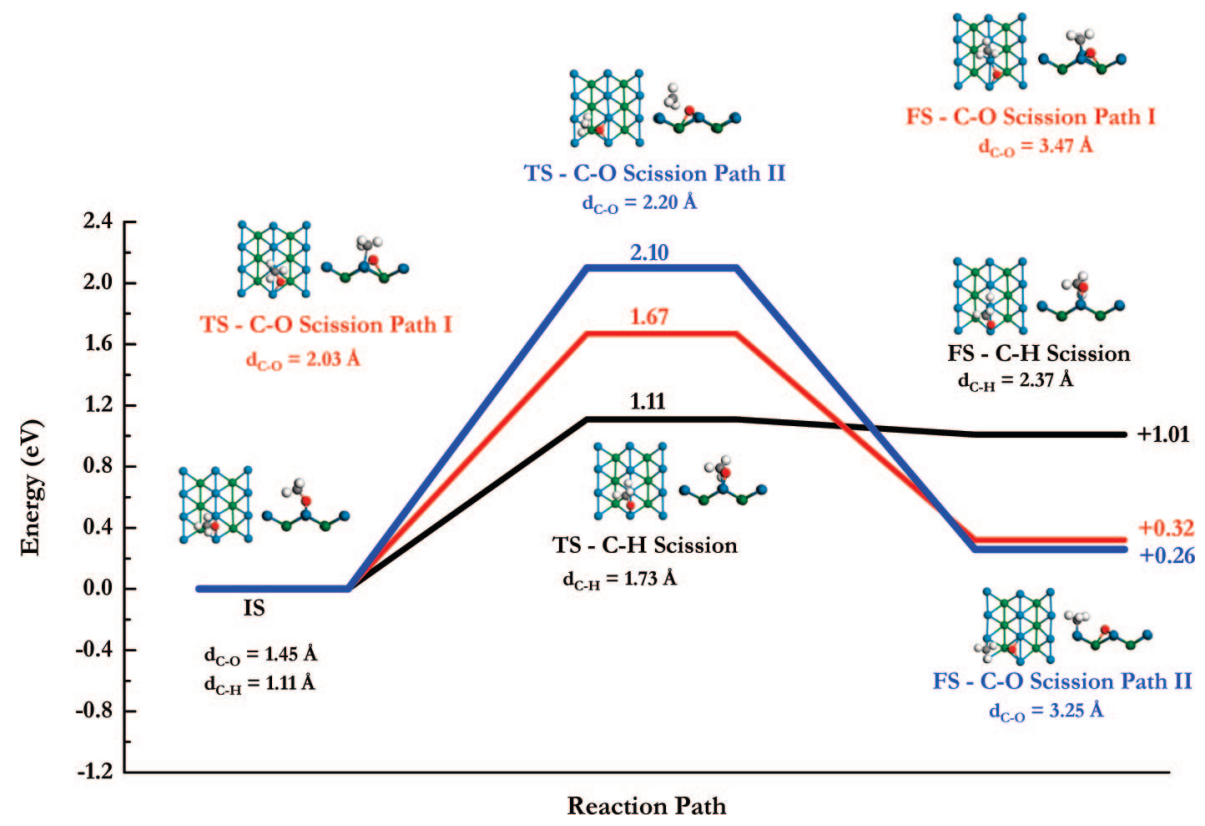

Figure 4. Reaction pathways of $\mathrm{CH}_{3} \mathrm{O}$.
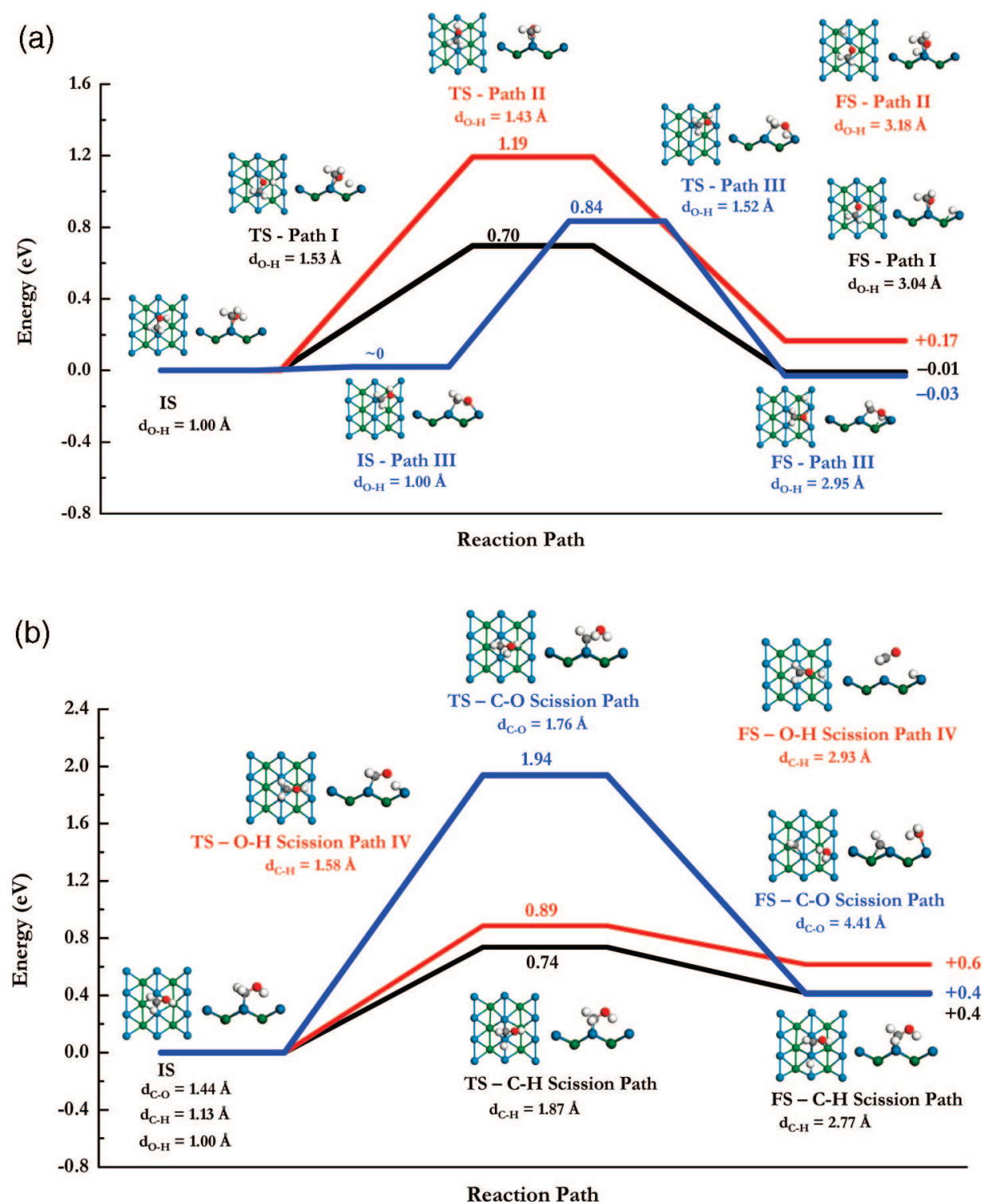

Figure 5. Reaction pathways of $\mathrm{CH}_{2} \mathrm{OH}$ : (a) $\mathrm{O}-\mathrm{H}$ scission; (b) $\mathrm{O}-\mathrm{H}, \mathrm{C}-\mathrm{H}$, and concurrent $\mathrm{C}-\mathrm{H}$ and $\mathrm{C}-\mathrm{O}$ scission. 
direction while the $\mathrm{CH}_{2} \mathrm{O}$ fragment remains at the short-bridge site. The distance between the $\mathrm{O}$ atom of the $\mathrm{CH}_{2} \mathrm{O}$ fragment and the hydroxyl $\mathrm{H}$ elongates to $1.53 \AA$ at the transition state. The activation barrier of $\mathrm{O}-\mathrm{H}$ bond scission of $\mathrm{CH}_{2} \mathrm{OH}$ in Path I is $0.70 \mathrm{eV}$. Path I is thermochemically neutral. In Path II, the $\mathrm{O}-\mathrm{H}$ bond breaks along the [1]10] direction. The activation barrier of Path II is $1.19 \mathrm{eV}$. Path II is slightly endothermic with the reaction energy of $+0.17 \mathrm{eV}$. In Path III, adsorbed $\mathrm{CH}_{2} \mathrm{OH}$ migrates from the short-bridge site to the long-bridge site before the $\mathrm{O}-\mathrm{H}$ bond breaks. Then the $\mathrm{O}-\mathrm{H}$ bond breaks along the $[1 \overline{1} 0]$ direction, yielding the coadsorbed $\mathrm{CH}_{2} \mathrm{O}$ at the long-bridge site and atomic $\mathrm{H}$ at the pseudo-fcc(111) site. The activation barrier of Path III is $0.84 \mathrm{eV}$. Like Path I, Path III is thermochemically neutral. Path IV of $\mathrm{O}-\mathrm{H}$ bond scission of $\mathrm{CH}_{2} \mathrm{OH}$ is shown in Figure 5b (labeled Path IV). Path IV is a reaction pathway that the dissociated $\mathrm{CH}_{2} \mathrm{O}$ will be released to the gas phase after $\mathrm{O}-\mathrm{H}$ bond scission. At the initial state of Path IV, $\mathrm{CH}_{2} \mathrm{OH}$ binds at the short-bridge site only through the $\mathrm{C}$ atom. The activation barrier of Path IV is $0.89 \mathrm{eV}$. The reaction energy of Path IV is $+0.62 \mathrm{eV}$. The high endothermicity of Path IV indicates that the reverse process that adsorption of formaldehyde with the preadsorbed atomic $\mathrm{H}$ forming $\mathrm{CH}_{2} \mathrm{OH}$ is very likely occurring on $\mathrm{Cu}(110)$.

3.2.3.2. $C-H$ Scission. The $\mathrm{C}-\mathrm{H}$ bond scission of $\mathrm{CH}_{2} \mathrm{OH}$ produces hydroxymethylene $(\mathrm{CHOH})$ and atomic $\mathrm{H}$. Only one pathway for $\mathrm{C}-\mathrm{H}$ bond scission is identified. As shown in Figure 5 b, this $\mathrm{C}-\mathrm{H}$ scission pathway starts with the $\mathrm{C}$-bonded $\mathrm{CH}_{2} \mathrm{OH}$ at the short bridge. As the $\mathrm{C}-\mathrm{H}$ bond breaks, the methylic $\mathrm{H}$ moves away from $\mathrm{CHOH}$ along the [1 $\overline{1} 0]$ direction. The activation barrier of $\mathrm{C}-\mathrm{H}$ scission in $\mathrm{CH}_{2} \mathrm{OH}$ is $0.74 \mathrm{eV}$. The reaction energy is $+0.42 \mathrm{eV}$.

3.2.3.3. Concurrent $\mathrm{C}-\mathrm{O}$ and $\mathrm{C}-\mathrm{H}$ Scissions. The reaction pathway for $\mathrm{C}-\mathrm{O}$ bond scission in $\mathrm{CH}_{2} \mathrm{OH}$ to yield methylene $\left(\mathrm{CH}_{2}\right)$ and $\mathrm{OH}$ is not identified in the present work. Instead, we identify an alternative pathway that $\mathrm{CH}_{2} \mathrm{OH}$ dissociates into methylidyne $(\mathrm{CH})$ and water $\left(\mathrm{H}_{2} \mathrm{O}\right)$ via both $\mathrm{C}-\mathrm{O}$ and $\mathrm{C}-\mathrm{H}$ bond scissions. When the $\mathrm{C}-\mathrm{O}$ bond of $\mathrm{CH}_{2} \mathrm{OH}$ is breaking, one of the $\mathrm{C}-\mathrm{H}$ bonds in $\mathrm{CH}_{2} \mathrm{OH}$ is also broken. The methylic $\mathrm{H}$ then recombines with the dissociated $\mathrm{OH}$ group forming $\mathrm{H}_{2} \mathrm{O}$. At the final state, $\mathrm{CH}$ binds at the pseudo-fcc(111) site and $\mathrm{H}_{2} \mathrm{O}$ binds at the top site with a slightly tilted orientation. Since this special reaction pathway involves two bond-breaking processes and one bond-making process, the activation barrier is very high $(1.94 \mathrm{eV})$. The calculated reaction energy is $+0.41 \mathrm{eV}$.

Comparing the activation barriers of the reaction pathways found for $\mathrm{CH}_{2} \mathrm{OH}$ dissociation on $\mathrm{Cu}(110)$, we find that the $\mathrm{O}-\mathrm{H}$ scission (Path $\mathrm{I}$ ) and the $\mathrm{C}-\mathrm{H}$ scission are competitive due to their similar barriers $(0.70 \mathrm{vs} 0.74 \mathrm{eV})$. This suggests that both $\mathrm{CH}_{2} \mathrm{O}$ and $\mathrm{CHOH}$ species can be formed via $\mathrm{CH}_{2} \mathrm{OH}$ decomposition. A reaction pathway, which releases $\mathrm{CH}_{2} \mathrm{O}$ into the gas phase, is also possible with a somewhat higher barrier of $0.89 \mathrm{eV}$, providing an alternate route for $\mathrm{CH}_{2} \mathrm{OH}$ formation from $\mathrm{CH}_{2} \mathrm{O}$. The direct formation via $\mathrm{C}-\mathrm{H}$ bond scission of $\mathrm{CH}_{3} \mathrm{OH}$ is unlikely.

3.2.4. Formaldehyde $\left(\mathrm{CH}_{2} \mathrm{O}\right)$ Decomposition. $\mathrm{CH}_{2} \mathrm{O}$ is the only experimentally observed product in $\mathrm{CH}_{3} \mathrm{OH}$ TPD on the clean $\mathrm{Cu}(110)$ surface. We find $\mathrm{CH}_{2} \mathrm{O}$ weakly binds at the shortbridge site through both $\mathrm{C}$ and $\mathrm{O}$ atoms. As shown in Figure 1d, the axis of adsorbed $\mathrm{CH}_{2} \mathrm{O}$ is slightly tilted away from the [110] direction. The $\mathrm{C}-\mathrm{Cu}$ and $\mathrm{O}-\mathrm{Cu}$ bond lengths are 2.21 and $2.05 \AA$, respectively. The binding energy of $\mathrm{CH}_{2} \mathrm{O}$ at the short-bridge site is $-0.41 \mathrm{eV}$. This is in good agreement with previous DFT result of $0.46 \mathrm{eV} \cdot{ }^{13} \mathrm{CH}_{2} \mathrm{O}$ also binds at the longbridge site on $\mathrm{Cu}(110)$. The binding energy of $\mathrm{CH}_{2} \mathrm{O}$ at the long- bridge site is $-0.52 \mathrm{eV}$. Our calculated binding energies of $\mathrm{CH}_{2} \mathrm{O}$ are slightly weaker than the experimental result of 0.59 eV. ${ }^{11}$ For $\mathrm{CH}_{2} \mathrm{O}$ decomposition, only two bond scissions $(\mathrm{C}-\mathrm{H}$ and $\mathrm{C}-\mathrm{O}$ ) are possible. Unfortunately, there are no theoretical calculations of $\mathrm{CH}_{2} \mathrm{O}$ decomposition on $\mathrm{Cu}(110)$ that we can compare with. The adsorbed $\mathrm{CH}_{2} \mathrm{O}$ at the short-bridge site is used as the initial state.

3.2.4.1. $\mathrm{C}-\mathrm{H}$ Scission. The $\mathrm{C}-\mathrm{H}$ bond scission of $\mathrm{CH}_{2} \mathrm{O}$ yields formyl $(\mathrm{CHO})$ and atomic $\mathrm{H}$. Starting with adsorbed $\mathrm{CH}_{2} \mathrm{O}$ at the short-bridge site, three possible reaction paths for the $\mathrm{C}-\mathrm{H}$ bond breaking are found. As shown in Figure 6a, all three paths are endothermic, indicating the reverse process that recombines $\mathrm{CHO}$ and atomic $\mathrm{H}$ forming $\mathrm{CH}_{2} \mathrm{O}$ is more favorable. Path I shows the $\mathrm{C}-\mathrm{H}$ bond breaks along the [001] direction. The coadsorbed $\mathrm{CHO}$ and atomic $\mathrm{H}$ bind at the shortbridge sites on separate uppermost rows in the final state of Path I. The activation barrier of Path I is $0.79 \mathrm{eV}$. In Path II, the $\mathrm{C}-\mathrm{H}$ bond breaks along the $[1 \overline{1} 0]$ direction. The activation barrier for Path II is $0.95 \mathrm{eV}$. Similar to the bond-breaking processes discussed above, this implies the $\mathrm{C}-\mathrm{H}$ bond breaking of $\mathrm{CH}_{2} \mathrm{O}$ along the [001] direction is preferred to that along [110]. The lowest energy mechanism, path III, consists of two steps. $\mathrm{CH}_{2} \mathrm{O}$ first diffuses from the short-bridge site to the longbridge site with a barrier is $0.47 \mathrm{eV}$. Then $\mathrm{CH}_{2} \mathrm{O}$ dissociates into $\mathrm{CHO}$ and atomic $\mathrm{H}$ with an activation barrier of $0.68 \mathrm{eV}$. In the final state, $\mathrm{CHO}$ binds at the long-bridge site and atomic $\mathrm{H}$ binds at the short-bridge site.

3.2.4.2. $\mathrm{C}-\mathrm{O}$ Scission. The $\mathrm{C}-\mathrm{O}$ bond scission of $\mathrm{CH}_{2} \mathrm{O}$ yields $\mathrm{CH}_{2}$ and atomic $\mathrm{O}$. Figure $6 \mathrm{~b}$ shows two such reaction pathways, both of which involve significant surface relaxation. At the transition state of Path I, atomic O binds at the pseudofcc(111) site while $\mathrm{CH}_{2}$ binds at the pseudo-bridge site. At the final state, $\mathrm{CH}_{2}$ binds at the short-bridge site and atomic $\mathrm{O}$ binds at the adjacent pseudo-fcc(111) site. The activation barrier of Path I is $1.28 \mathrm{eV}$. Path I is endothermic with the reaction energy of $+0.51 \mathrm{eV}$. Path II is similar to the Path III of $\mathrm{C}-\mathrm{H}$ bond scission of $\mathrm{CH}_{2} \mathrm{O} . \mathrm{CH}_{2} \mathrm{O}$ diffuses from the short-bridge site to the long-bridge site; the $\mathrm{C}-\mathrm{O}$ bond is broken; and in the final state, $\mathrm{CH}_{2}$ binds at the long-bridge site and the atomic $\mathrm{O}$ binds the pseudo-fcc(111) site. The activation barrier of Path II is very high $(1.82 \mathrm{eV})$. In conclusion, the most favorable dissociation path for $\mathrm{CH}_{2} \mathrm{O}$ is via $\mathrm{C}-\mathrm{H}$ bond scission leading to $\mathrm{CHO}$ and atomic H, i.e., the Path III in Figure 6a.

3.2.5. Hydroxymethylene (CHOH) Decomposition. Experimental information of $\mathrm{CHOH}$ interacting with metal surfaces has not been reported before. However, it is important to keep in mind that many reaction intermediates cannot be observed by spectroscopic techniques because they are highly reactive and have short lifetimes on the surface. A DFT study suggested that $\mathrm{CHOH}$ adsorbs at the 3-fold hollow site on $\mathrm{Cu}(111)$ through the $\mathrm{C}$ atom. ${ }^{25}$ Other slab DFT calculation indicated that $\mathrm{CHOH}$ adsorbs on the bridge site on $\mathrm{Pt}(111) .{ }^{24}$ Our calculations show that $\mathrm{CHOH}$ prefers to bind at the short-bridge site on $\mathrm{Cu}(110)$ through the $\mathrm{C}$ atom. At the short-bridge site, two orientations of the $\mathrm{CHOH}$ hydroxyl have been identified. The hydroxyl $\mathrm{H}$ atom can either point away from the surface (Figure 1e) or toward the surface (Figures 2f). As expected, the configuration with hydroxyl $\mathrm{H}$ atom pointing to the surface is slightly more stable (by $0.21 \mathrm{eV}$ ). The rotation barrier between these states is $0.26 \mathrm{eV}$. Besides the short-bridge site, $\mathrm{CHOH}$ can also bind at the top site (Figures 2g) and the long-bridge site (Figure 2h) with the binding energies of -2.50 and $-2.24 \mathrm{eV}$.

3.2.5.1. $\mathrm{O}-\mathrm{H}$ Scission. The $\mathrm{O}-\mathrm{H}$ bond scission of $\mathrm{CHOH}$ yields $\mathrm{CHO}$ and atomic $\mathrm{H}$. Three $\mathrm{O}-\mathrm{H}$ bond scission pathways 


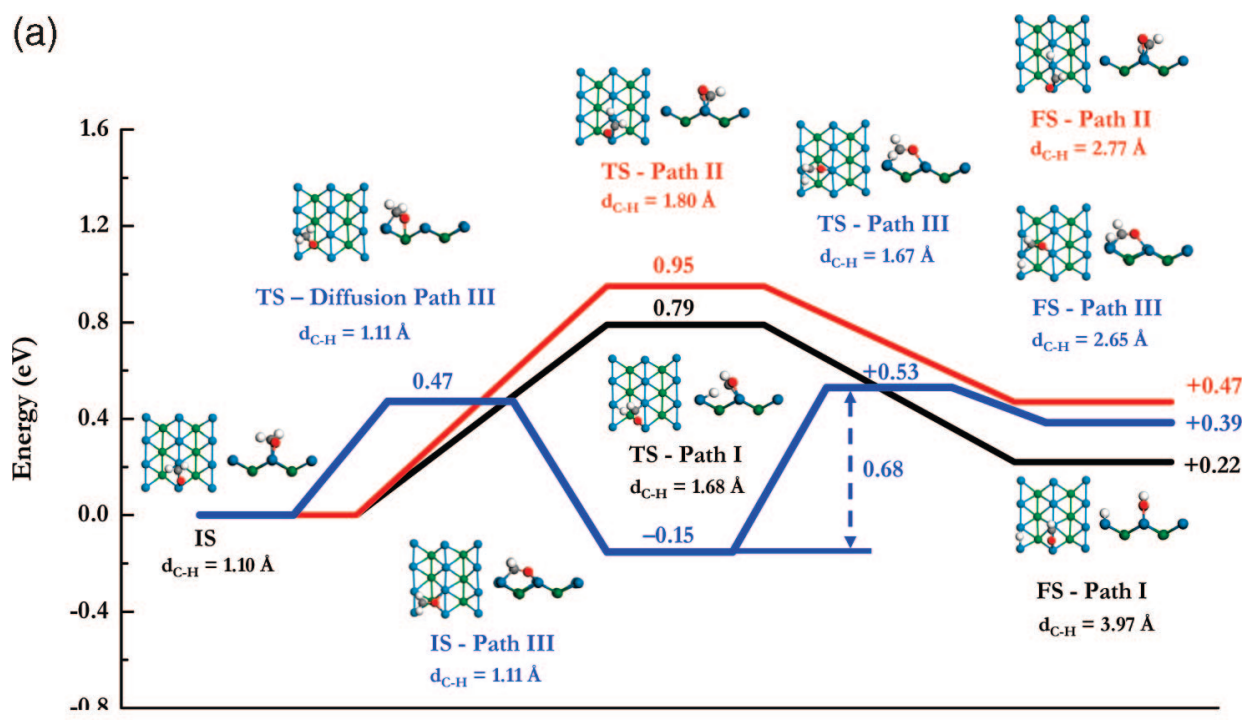

(b)

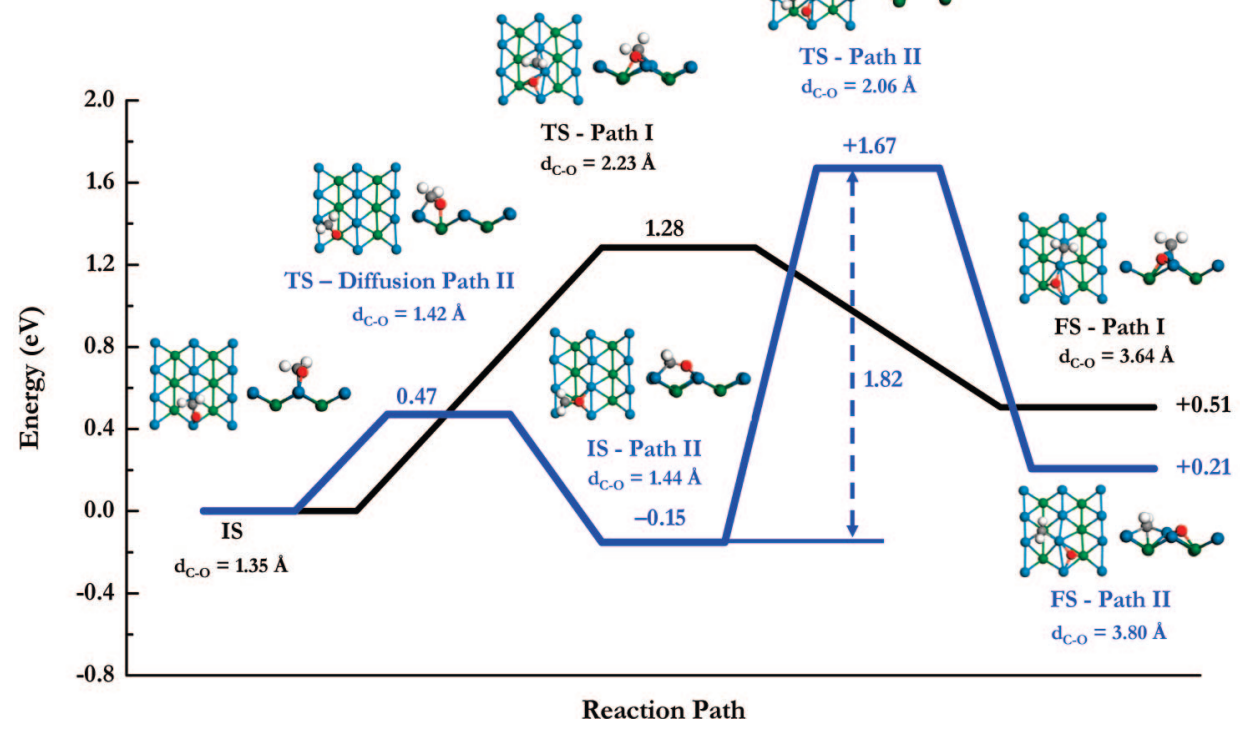

Figure 6. Reaction pathways of $\mathrm{CH}_{2} \mathrm{O}$ : (a) $\mathrm{C}-\mathrm{H}$ scission; (b) $\mathrm{C}-\mathrm{O}$ scission.

with different initial states for $\mathrm{CHOH}$ have been identified in this work. The most favorable path is Path I (see Figure 7a), in which $\mathrm{CHOH}$ at the short-bridge site dissociates into $\mathrm{CHO}$ at the short-bridge site and atomic $\mathrm{H}$ at the pseudo-fcc(111) site. The activation barrier of Path $\mathrm{I}$ is $0.70 \mathrm{eV}$, and the reaction energy is $+0.29 \mathrm{eV}$. The Path II of $\mathrm{O}-\mathrm{H}$ scission begins with the adsorbed $\mathrm{CHOH}$ at the top site. The initial state in Path II is $0.26 \mathrm{eV}$ less stable than the initial state in Path $\mathrm{I}$. The $\mathrm{O}-\mathrm{H}$ bond breaks along the [1실 direction. At the final state, $\mathrm{CHO}$ binds at the short-bridge site through the $\mathrm{C}$ atom and atomic $\mathrm{H}$ binds at the adjacent pseudo-fcc(111) site. The activation barrier of Path II is $1.18 \mathrm{eV}$ and the reaction pathway is endothermic with the reaction energy of $+0.60 \mathrm{eV}$. The Path III of $\mathrm{O}-\mathrm{H}$ bond scission of $\mathrm{CHOH}$ begins with the initial state that $\mathrm{CHOH}$ binds at the long-bridge site. Although the activation barrier for Path III is $0.59 \mathrm{eV}$, smaller than the barrier of Path I, the initial state of Path III is $0.56 \mathrm{eV}$ less stable than the corresponding initial state of Path I. As a result, the total barrier of Path III is at least $1.15 \mathrm{eV}$. Therefore, Path I is the favorable pathway for $\mathrm{O}-\mathrm{H}$ scission of $\mathrm{CHOH}$.

3.2.5.2. $C-H$ Scission. The second possible $\mathrm{CHOH}$ decomposition path is via $\mathrm{C}-\mathrm{H}$ bond scission, producing hydroxym- ethylidyne $(\mathrm{COH})$ and atomic $\mathrm{H}$. Three pathways (all endothermic) are shown in Figure 7b. In Path I, the C-bonded $\mathrm{CHOH}$ at the short-bridge moves to the trough along the [001]direction as the $\mathrm{C}-\mathrm{H}$ bond breaks. In the final state, both $\mathrm{COH}$ and atomic $\mathrm{H}$ bind at adjacent pseudo-fcc(111) sites. The $\mathrm{C}-\mathrm{H}$ bondbreaking barrier of Path I is $1.02 \mathrm{eV}$. In Path II, $\mathrm{COH}$ and atomic $\mathrm{H}$ move in the opposite direction, dissociating with an activation barrier of $1.14 \mathrm{eV}$. Path II is highly endothermic so that the dissociated $\mathrm{COH}$ and $\mathrm{H}$ will quickly recombine to form $\mathrm{CHOH}$. In the third path, the hydroxyl $\mathrm{H}$ initially rotates from an upward direction to a downward direction (pointing at the surface) before the $\mathrm{C}-\mathrm{H}$ bond breaks. In the final state, $\mathrm{COH}$ binds at the pseudo-fcc(111) site while atomic $\mathrm{H}$ binds at the short-bridge site. The activation barrier for Path III is $1.36 \mathrm{eV}$, which is higher than the barriers of paths I and II.

3.2.5.3. $\mathrm{C}-\mathrm{O}$ Scission. Three pathways for $\mathrm{C}-\mathrm{O}$ bond scission of $\mathrm{CHOH}$ were identified (see Figure 7c), each yielding methylidyne $(\mathrm{CH})$ and $\mathrm{OH}$. In Path $\mathrm{I}, \mathrm{CHOH}$ moves to the trough along the [001]direction. At the transition state, both $\mathrm{CH}$ and $\mathrm{OH}$ bind at the pseudo-fcc(111) sites. Then $\mathrm{OH}$ group continues to move along the [001]direction and finally binds at the short-bridge site on the cross row while $\mathrm{CH}$ remains at the 
(a)

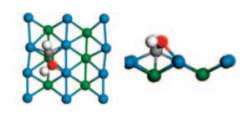

IS - Path III $\mathrm{d}_{\mathrm{O}-\mathrm{H}}=1.00 \AA$
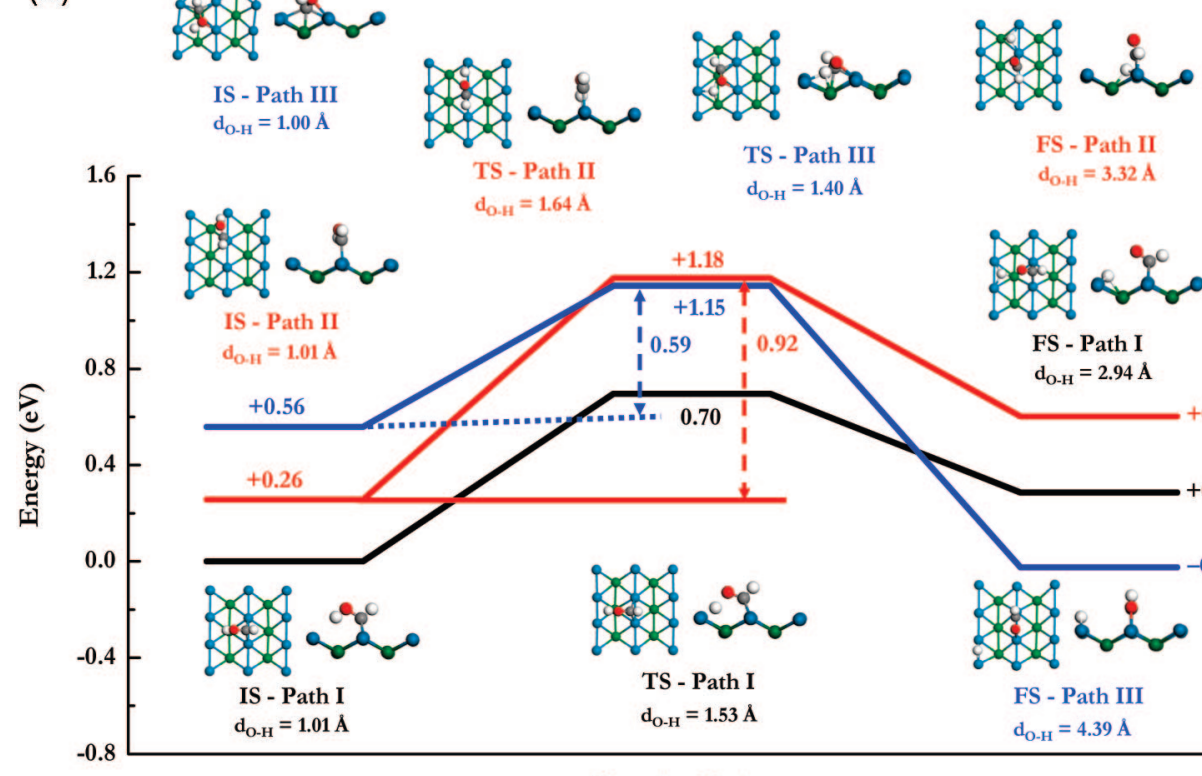

(b)

(b)

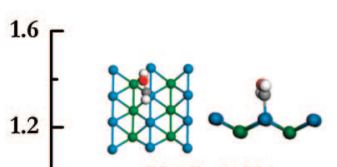

$\mathrm{d}_{\mathrm{O} \cdot \mathrm{H}}=1.64 \mathrm{~A}$

$\mathrm{d}_{\mathrm{O}-\mathrm{H}}=1.40 \AA$

$\mathrm{d}_{\mathrm{O}-\mathrm{H}}=3.32 \mathrm{~A}$

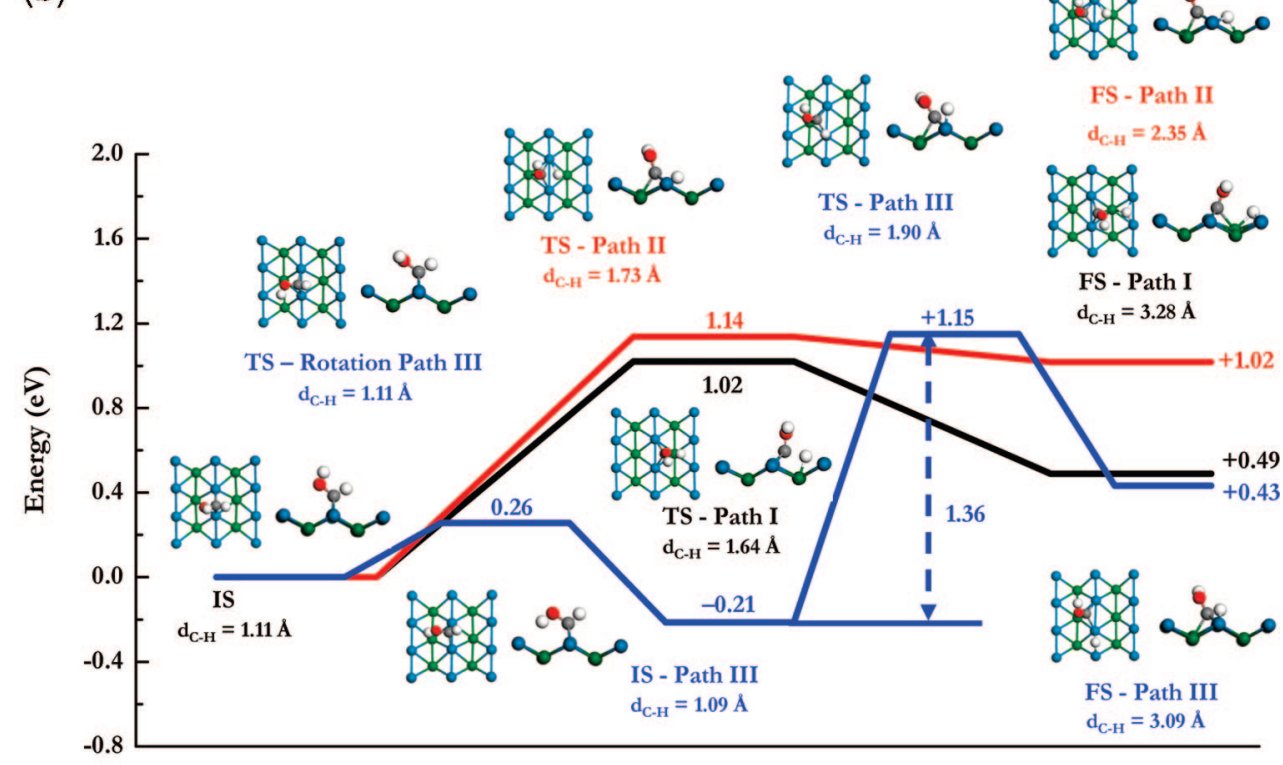

Reaction Path

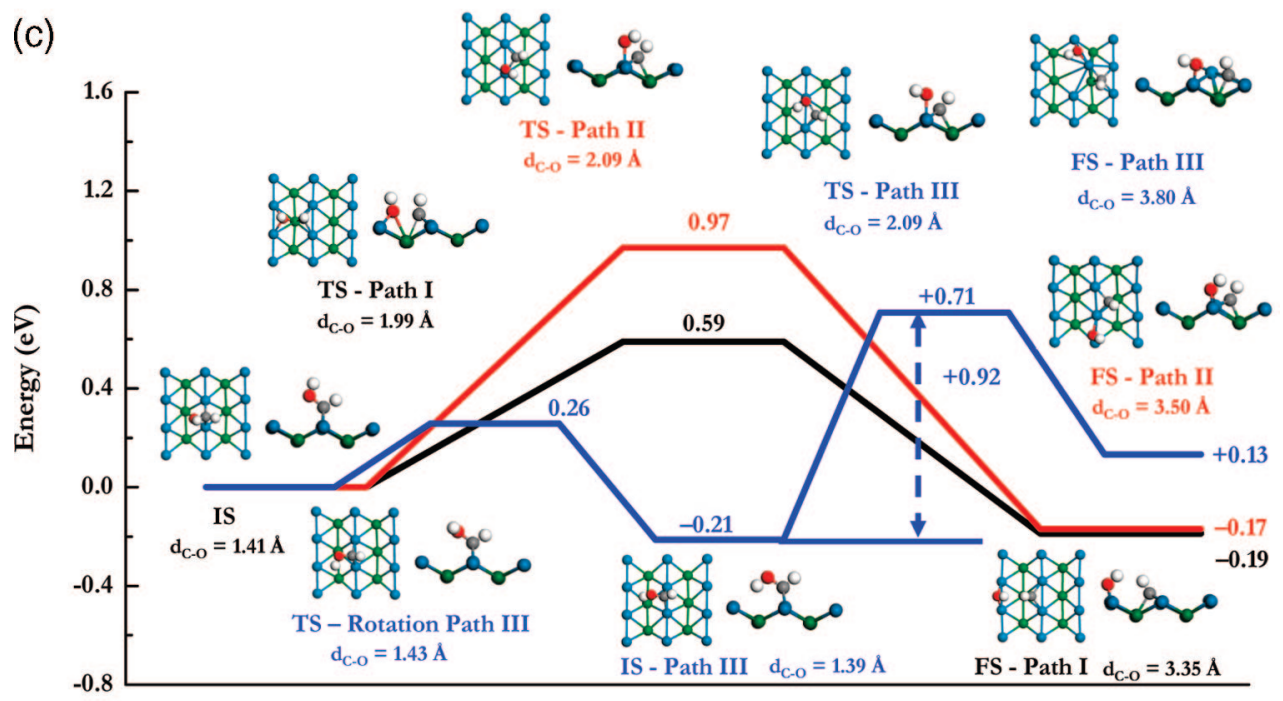

Reaction Path

Figure 7. Reaction pathways of $\mathrm{CHOH}$ : (a) $\mathrm{O}-\mathrm{H}$ scission; (b) $\mathrm{C}-\mathrm{H}$ scission; (c) $\mathrm{C}-\mathrm{O}$ scission. 

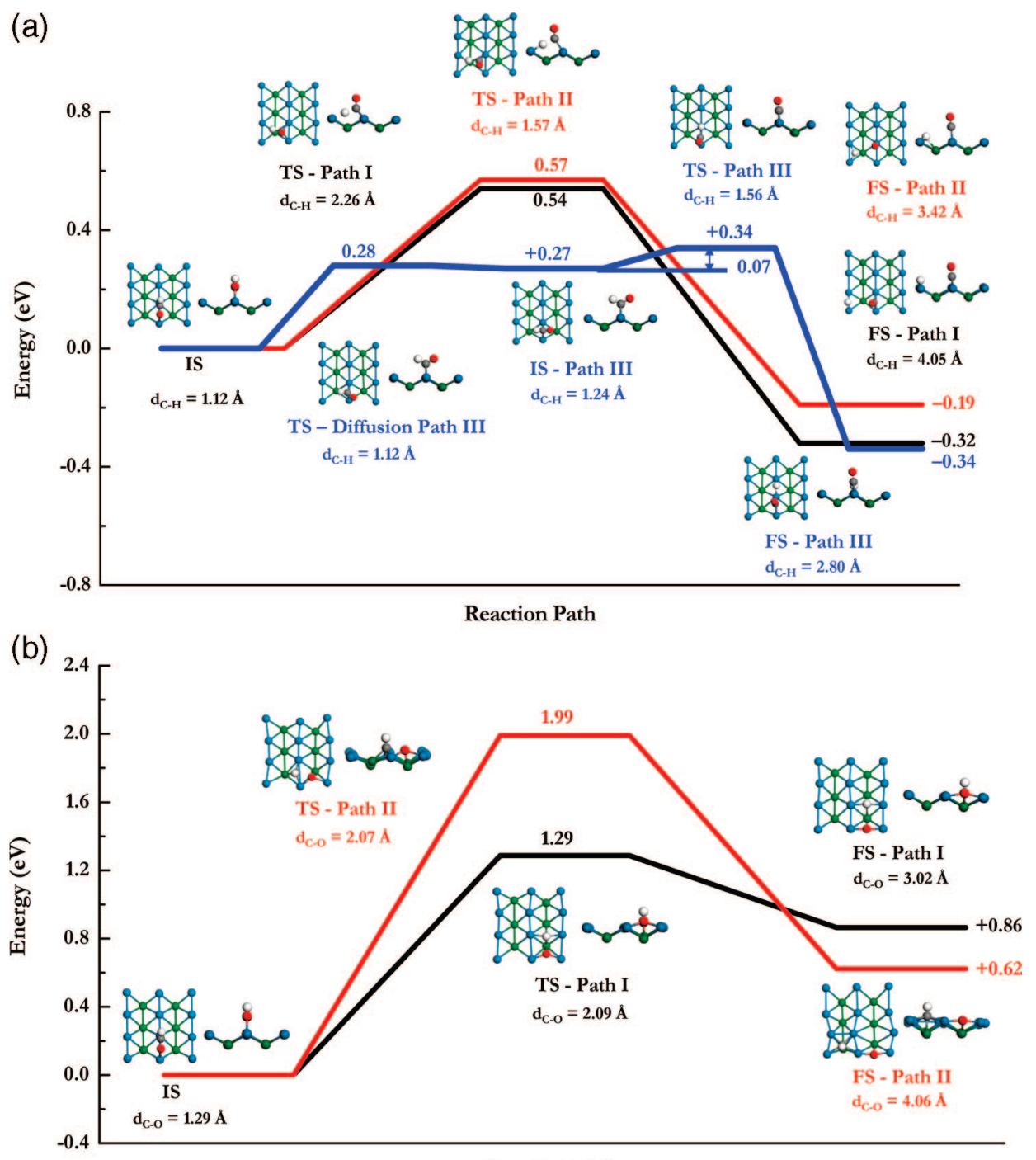

Reaction Path

Figure 8. Reaction pathways of $\mathrm{CHO}$ : (a) $\mathrm{C}-\mathrm{H}$ scission; (b) $\mathrm{C}-\mathrm{O}$ scission.

original pseudo-fcc(111) site. The activation barrier of Path I is $0.59 \mathrm{eV}$. In Path II, instead of moving along the [001] direction, $\mathrm{CHOH}$ moves along the $[1 \overline{1} 0]$ direction as the $\mathrm{C}-\mathrm{O}$ bond breaks. The final state is the coadsorbed $\mathrm{CH}$ binding at the pseudo-fcc(111) site and $\mathrm{OH}$ binding at the short-bridge site through the $\mathrm{O}$ atom. Although the reaction energies of Path I and II are close $(-0.19$ and $-0.17 \mathrm{eV})$, the activation barrier of Path II is higher $(0.97 \mathrm{eV})$. Path III goes through an $\mathrm{H}$ rotation process before the $\mathrm{C}-\mathrm{O}$ bond breaking. We note that a significant surface relaxation is observed in Path III. One of uppermost $\mathrm{Cu}$ atoms on the surface is lifted off and moved right over the trough. This can be attributed to the strong interaction between $\mathrm{CH}$ and $\mathrm{Cu}(110)$. A complex of $\mathrm{CH}-\mathrm{Cu}-\mathrm{OH}$ configuration is formed at the final state of Path III. The activation barrier of Path III is $0.92 \mathrm{eV}$ and is endothermic by $+0.34 \mathrm{eV}$. Comparing all reaction pathways found for $\mathrm{CHOH}$ decomposition, Path $\mathrm{I}$ of $\mathrm{C}-\mathrm{O}$ bond scission is slightly preferred, but might be competitive with Path $\mathrm{I}$ of $\mathrm{O}-\mathrm{H}$ bond scission. This indicates that both $\mathrm{CH}$ and $\mathrm{CHO}$ are the possible products by $\mathrm{CHOH}$ decomposition on $\mathrm{Cu}(110)$.

3.2.6. Formyl (CHO) Decomposition. As far as we know, no direct experimental spectroscopic signature of $\mathrm{CHO}$ had ever been reported in methanol decomposition on transition-metal surfaces. This is due to the fact that $\mathrm{CHO}$ is a radical species which is highly reactive on the surface. ${ }^{15}$ Theoretical investiga- tions have been performed to provide energetic and structural information of $\mathrm{CHO}$ adsorption on metal surfaces. Previous cluster and slab DFT calculations suggested that $\mathrm{CHO}$ binds at 3-fold hollow site on $\mathrm{Cu}(111)$ through the $\mathrm{C}$ atom. ${ }^{15,25,26} \mathrm{We}$ identify three stable adsorption positions for $\mathrm{CHO}$ on $\mathrm{Cu}(110)$ in the present work. The most stable configuration which is shown in Figure $2 \mathrm{i}$ has $\mathrm{CHO}$ adsorbed at the long-bridge site through both the $\mathrm{C}$ and $\mathrm{O}$ atoms with a binding energy of -2.80 $\mathrm{eV}$. CHO can also bind at the short-bridge site with both $\mathrm{C}$ and $\mathrm{O}$ atoms (Figure 1f) or through the $\mathrm{C}$ atom only (Figure $2 \mathrm{j}$ ), binding with -2.47 and $-2.21 \mathrm{eV}$, respectively. There are no DFT calculations of $\mathrm{CHO}$ adsorption on $\mathrm{Cu}(110)$ reported that we can compare with. The reported binding energies of $\mathrm{CHO}$ on $\mathrm{Cu}(111)$ are in the range of $1.15-1.45 \mathrm{eV} ;{ }^{15,25,26}$ therefore, it is clear that the adsorption of $\mathrm{CHO}$ on $\mathrm{Cu}(110)$ is much stronger. The adsorbed $\mathrm{CHO}$ at the short-bridge site with both $\mathrm{C}-\mathrm{Cu}$ and $\mathrm{O}-\mathrm{Cu}$ bonds is chosen as the initial state to explore its decomposition pathways. Two bond scissions $(\mathrm{C}-\mathrm{O}$ and $\mathrm{C}-\mathrm{H}$ ) of $\mathrm{CHO}$ are possible for $\mathrm{CHO}$ decomposition.

3.2.6.1. $C-H$ Scission. First, we discuss the pathways for the $\mathrm{C}-\mathrm{H}$ scission of $\mathrm{CHO}$. As shown in Figure $8 \mathrm{a}, \mathrm{CHO}$ dissociates into $\mathrm{CO}$ and atomic $\mathrm{H}$ via $\mathrm{C}-\mathrm{H}$ bond scission by three different pathways. In Path I, CO binds at the short-bridge site and atomic $\mathrm{H}$ binds at the short-bridge site on the cross row at the final state; while $\mathrm{CO}$ binds at the top site and atomic 
$\mathrm{H}$ binds at the pseudo-fcc(111) site in Path II. The activation barriers for Path I and II are very close; $0.54 \mathrm{eV}$ for Path I and $0.57 \mathrm{eV}$ for Path II, and are exothermic with reaction energies of -0.32 and $-0.19 \mathrm{eV}$, respectively. In the third path, $\mathrm{CHO}$ rotates from the [1필 to the [001] direction and, as a result, switches from double $\mathrm{C}-\mathrm{Cu}$ and $\mathrm{O}-\mathrm{Cu}$ bonding to single $\mathrm{C}-\mathrm{Cu}$ bonding at the short-bridge site. The diffusion barrier for this rotation process is $0.28 \mathrm{eV}$. We note that $\mathrm{CHO}$ adsorbed at the short-bridge site through single $\mathrm{C}-\mathrm{Cu}$ bonding is unstable since there is a negligible reverse barrier. Therefore, the single $\mathrm{C}-\mathrm{Cu}$ bond at the short-bridge site can also be considered an intermediate state in the $\mathrm{C}-\mathrm{H}$ bond scission. From this intermediate state, the $\mathrm{C}-\mathrm{H}$ bond scission of $\mathrm{CHO}$ in Path III is nearly spontaneous with an activation barrier of only 0.07 $\mathrm{eV}$. The total activation barrier for $\mathrm{C}-\mathrm{H}$ bond scission in Path III is $0.35 \mathrm{eV}$, making it the most favorable.

3.2.6.2. $\mathrm{C}-\mathrm{O}$ Scission. The $\mathrm{C}-\mathrm{O}$ bond scission of $\mathrm{CHO}$ yields $\mathrm{CH}$ and atomic $\mathrm{O}$. Figure $8 \mathrm{~b}$ shows two identified reaction pathways for $\mathrm{C}-\mathrm{O}$ bond scission of $\mathrm{CHO}$. In Path $\mathrm{I}$, the shortbridge bonded $\mathrm{CHO}$ moves to the trough along the [001] direction as the $\mathrm{C}-\mathrm{O}$ bond breaks. At the transition state, both $\mathrm{CH}$ and atomic $\mathrm{O}$ binds at the long-bridge sites with the $\mathrm{C}-\mathrm{O}$ distance of $2.09 \AA$. The activation barrier for Path I is $1.29 \mathrm{eV}$ and the reaction is endothermic $(+0.86 \mathrm{eV})$. Path $\mathrm{I}$ is a productlike reaction pathway because the geometrical configurations of the transition state and the final state are similar. In Path II, the atomic $\mathrm{O}$ moves to the long-bridge site while the $\mathrm{CH}$ group moves to adjacent pseudo-fcc(111) site in the opposite direction when the $\mathrm{C}-\mathrm{O}$ bond breaks. As shown in Figure 8b, a pronounced surface relaxation of $\mathrm{Cu}(110)$ is observed in Path II. At the final state, both $\mathrm{CH}$ and atomic $\mathrm{O}$ bind at the longbridge sites sharing one uppermost $\mathrm{Cu}$ atom. It is generally observed from the calculations of this work that the significant surface relaxation (reconstruction) occurs when the products involving unsaturated hydrocarbon species $\left(\mathrm{CH}_{\mathrm{x}}\right)$. Path II is endothermic with the reaction energy of $+0.62 \mathrm{eV}$. The activation barrier of in Path II is very high $(1.99 \mathrm{eV})$ so that the process is unlikely. Compared with the calculated activation barriers of different pathways for both $\mathrm{C}-\mathrm{H}$ and $\mathrm{C}-\mathrm{O}$ bond scissions of $\mathrm{CHO}$, the $\mathrm{C}-\mathrm{H}$ bond scission of $\mathrm{CHO}$ leading to $\mathrm{CO}$ and atomic $\mathrm{H}$ is the dominated pathway for $\mathrm{CHO}$ decomposition on $\mathrm{Cu}(110)$.

3.2.7. Hydroxymethylidyne (COH) Decomposition. $\mathrm{COH}$ species is the product of $\mathrm{HCOH}$ decomposition via $\mathrm{C}-\mathrm{H}$ bond scission. Previous cluster and periodic DFT studies of $\mathrm{COH}$ on $\mathrm{Pt}(111)$ and $\mathrm{Cu}(111)$ suggest that $\mathrm{COH}$ binds at a 3-fold hollow site through the $\mathrm{C}$ atom. ${ }^{25}$ In agreement with these theoretical results, the most stable adsorption site for $\mathrm{COH}$ on $\mathrm{Cu}(110)$ is the pseudo-fcc(111) site. As shown in Figure 1g, the $\mathrm{C}-\mathrm{O}$ axis of adsorbed $\mathrm{COH}$ is tilted by $35^{\circ}$ with respect to the surface normal. The angle of $\mathrm{C}-\mathrm{O}-\mathrm{H}$ is $111^{\circ}$. The three $\mathrm{C}-\mathrm{Cu}$ bond lengths are $2.11,1.91$, and $1.91 \AA$. The binding energy of adsorbed $\mathrm{COH}$ at the pseudo-fcc(111) site is $-3.48 \mathrm{eV}$, indicating that $\mathrm{COH}$ binds on $\mathrm{Cu}(110)$ stronger than on $\mathrm{Cu}(111)$ with the binding energy of $-2.95 \mathrm{eV} .{ }^{25} \mathrm{COH}$ can also bind upright at the long-bridge site with two $\mathrm{C}-\mathrm{Cu}$ bonds (Figure $2 \mathrm{k}$ ). The binding energy of $\mathrm{COH}$ at the long-bridge is -3.24 $\mathrm{eV}$, slightly weaker than the pseudo-fcc(111) site. The diffusion barrier for $\mathrm{COH}$ moving from the pseudo-fcc(111) site to the long-bridge site is $0.34 \mathrm{eV}$. We find that $\mathrm{COH}$ stays at pseudobridge site at the transition state in the diffusion. The barrier for the reverse diffusion path is only $0.11 \mathrm{eV}$, indicating that $\mathrm{COH}$ prefers to stay at the most stable pseudo-fcc(111) site. The pseudo-fcc(111) site is used as the initial state for searching the possible reaction pathways of $\mathrm{COH}$ decomposition. The $\mathrm{O}-\mathrm{H}$ and $\mathrm{C}-\mathrm{O}$ bond scissions of $\mathrm{COH}$ are possible for $\mathrm{COH}$ decomposition.

3.2.7.1. $\mathrm{O}-\mathrm{H}$ Scission. The $\mathrm{O}-\mathrm{H}$ bond scission of $\mathrm{COH}$ produces $\mathrm{CO}$ and atomic $\mathrm{H}$. Two reaction pathways of $\mathrm{O}-\mathrm{H}$ scission shown in Figure 9a are found. In Path $\mathrm{I}$, the $\mathrm{O}-\mathrm{H}$ bond scission begins with the rotation of hydroxyl $\mathrm{H}$ atom of $\mathrm{COH}$ from the [110] direction to the [001] direction. At the transition state, the $\mathrm{O}-\mathrm{H}$ bond is already broken since the distance between $\mathrm{O}$ and $\mathrm{H}$ is $1.23 \AA$. After the transition state, atomic $\mathrm{H}$ continues to move away from $\mathrm{CO}$ and finally binds at the shortbridge site while $\mathrm{CO}$ also moves from the pseudo-fcc(111) site to the short-bridge site with an upright orientation at the final state. The activation barrier of Path I is $0.34 \mathrm{eV}$, and the reaction energy is $-1.06 \mathrm{eV}$, highly exothermic. In Path II, the $\mathrm{O}-\mathrm{H}$ bond breaking starts with the $\mathrm{H}$ atom of $\mathrm{COH}$ moving to the adjacent short-bridge site along the [1 $\overline{1} 0]$ direction. At the final state, both atomic $\mathrm{H}$ and $\mathrm{CO}$ bind at the adjacent short-bridge sites. Although the reaction energies of Path I and II are nearly the same, the activation barrier of Path II is higher $(0.91 \mathrm{eV})$, indicating that Path $\mathrm{I}$ is the preferred reaction pathway for the $\mathrm{O}-\mathrm{H}$ bond. The activation barrier of $\mathrm{COH}$ dehydrogenation to $\mathrm{CO}$ and $\mathrm{H}$ was calculated as $1.05 \mathrm{eV}$ on $\mathrm{Cu}(111) .{ }^{25}$ The $\mathrm{O}-\mathrm{H}$ scission path of $\mathrm{COH}$ on $\mathrm{Cu}(111)$ is also highly exothermic $(-1.19 \mathrm{eV}) .^{25}$

3.2.7.2. $\mathrm{C}-\mathrm{O}$ Scission. The $\mathrm{C}-\mathrm{O}$ bond scission of $\mathrm{COH}$ yields carbon $(\mathrm{C})$ and $\mathrm{OH}$. Three possible $\mathrm{C}-\mathrm{O}$ bond scission pathways have been identified. Path I and Path II begin with the most stable pseudo-fcc(111) site. In Path III, COH migrates to the long-bridge site where the bond-breaking occurs. As mentioned previously, we attribute the significant surface relaxation of $\mathrm{Cu}(110)$ induced by the formation of the unsaturated hydrocarbon species to the strong interaction between $\mathrm{C}$ and the $\mathrm{Cu}(110)$ surface. A pronounced surface relaxation observed in the final states of Path I and II further confirms this. As shown in Figure 9b, after the $\mathrm{C}-\mathrm{O}$ bond breaking, the $\mathrm{C}$ atom at the pseudo-fcc(111) site further moves inward to the $\mathrm{Cu}(110)$ surface, yielding two bonded $\mathrm{Cu}$ atoms, one in the uppermost row and another in the second row, that migrate away from their original equilibrium positions. As a result, the pseudofcc(111) site becomes the pseudo-4-fold hollow site. A similar trend that the barrier for the bond-breaking process along the [001] direction is lower than that along the [1시 direction on $\mathrm{Cu}(110)$ is found again. The $\mathrm{C}-\mathrm{O}$ scission along the [001] direction has a lower activation barrier. The activation barrier for Path I is $1.14 \mathrm{eV}$, which is lower than the barrier of 1.59 $\mathrm{eV}$ in Path II. Path III starts with adsorbed $\mathrm{COH}$ on the longbridge site. As the $\mathrm{C}-\mathrm{O}$ bond breaks, the $\mathrm{C}$ atom still stays at the long-bridge site and the $\mathrm{OH}$ group moves to the bridge fcc(111) site at the transition state. $\mathrm{OH}$ group binds at the shortbridge site in the final state. However, we note that little surface relaxation is found in Path III. The activation barrier of Path III is $0.81 \mathrm{eV}$, which is lower than the barriers of Path I and II, indicating that Path III is the most favorable path for the $\mathrm{C}-\mathrm{O}$ bond scission of $\mathrm{COH}$. Interestingly, although the barriers of three $\mathrm{C}-\mathrm{O}$ scission pathways of $\mathrm{COH}$ are quite different, all three reaction pathways are nearly thermochemically neutral. The reaction energies of three paths are $+0.14,-0.15$, and $+0.16 \mathrm{eV}$, respectively.

Because the lowest activation barrier pathway of $\mathrm{C}-\mathrm{O}$ bond scission in $\mathrm{COH}$ is still much higher than the barrier for $\mathrm{O}-\mathrm{H}$ scission pathways, it is expected that $\mathrm{COH}$ decomposition proceeds via $\mathrm{O}-\mathrm{H}$ bond scission, yielding $\mathrm{CO}$ and atomic $\mathrm{H}$. 

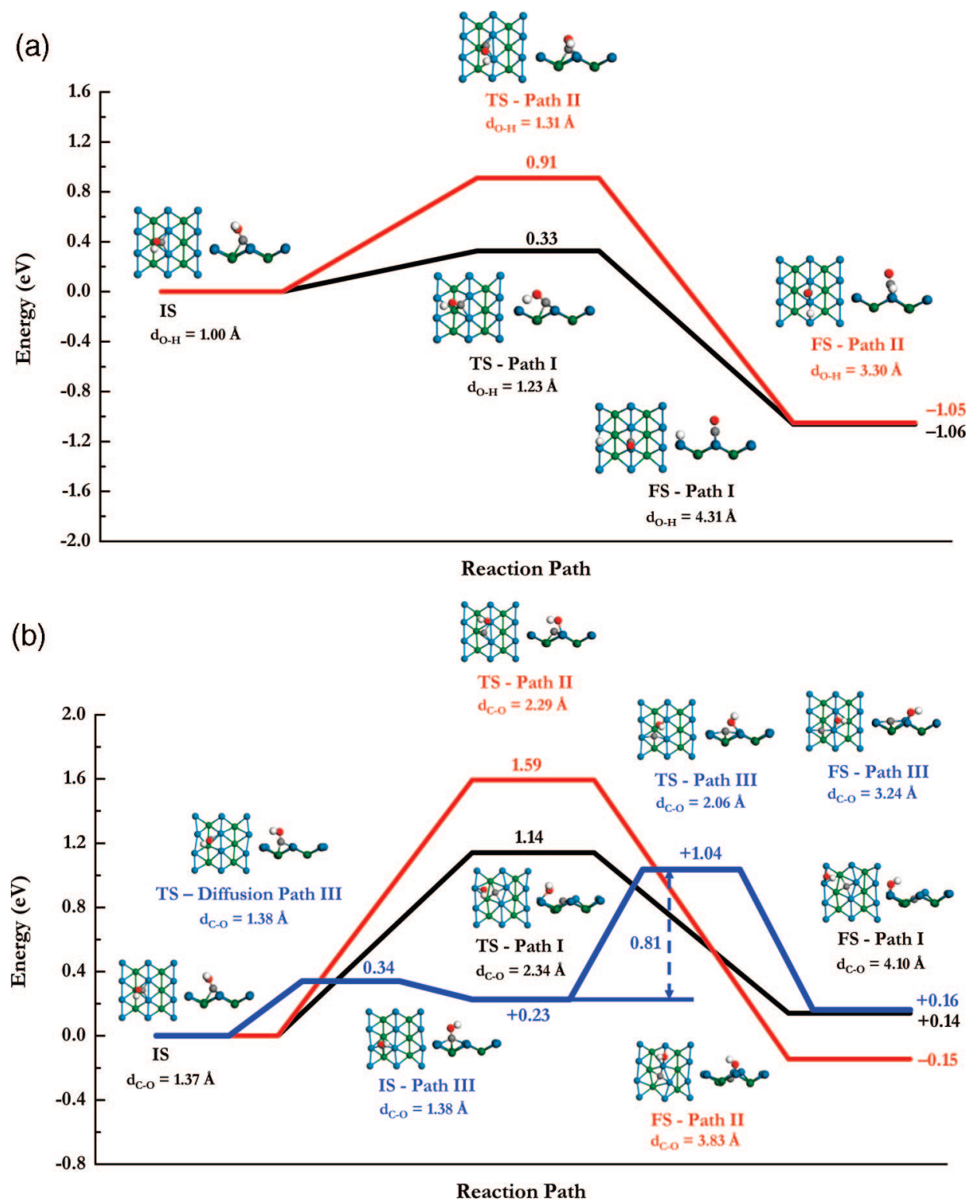

Figure 9. Reaction pathways of $\mathrm{COH}$ : (a) $\mathrm{O}-\mathrm{H}$ scission; (b) $\mathrm{C}-\mathrm{O}$ scission.

Our results suggest that the formation of carbon species on $\mathrm{Cu}(110)$ is unlikely, which is consistent with previous experiments. $^{27}$

\section{Discussion}

Methanol is the simplest molecular form of alcohol. Methanol decomposition is also a good prototype reaction for illustrating the computational method used in this work by showing how many reaction events are possible for even a small molecule on a single-crystal metal surface. Although only partial decomposition of methanol is observed experimentally on $\mathrm{Cu}(110)$, we have mapped out a more complete landscape for the decomposition of methanol and its decomposition products. The focus of this work is to demonstrate a method which can be used to automatically determine complex networks of reaction pathways. Different conditions such as temperature, pressure, and the presence of oxygen on the surface could alter the dominant pathway through the network. Figure 10 shows the reaction network of methanol decomposition on $\mathrm{Cu}(110)$. The activation barrier and the reaction energy of the pathway with the lowest barrier for each decomposition step are used. It is clear that adsorbed methanol most favorably proceeds as follows: $\mathrm{CH}_{3} \mathrm{OH} \rightarrow \mathrm{CH}_{3} \mathrm{O} \rightarrow \mathrm{CH}_{2} \mathrm{O}$. Formaldehyde would desorb from the $\mathrm{Cu}(110)$ surface rather than continue to dehydrogenate into $\mathrm{CO}$. After the initial $\mathrm{O}-\mathrm{H}$ bond scission of methanol, three consecutive $\mathrm{C}-\mathrm{H}$ bond scissions are most likely to occur. The rate-limiting step in this methanol decomposition route is the abstraction of a methylic hydrogen from methoxy; the barrier for $\mathrm{C}-\mathrm{H}$ bond scission of methoxy to formaldehyde is at least $0.5 \mathrm{eV}$ higher than the other step in this route. This is consistent with experimental observations that methoxy was found as the most abundant surface intermediate on the $\mathrm{Cu}(110)$ surface..$^{7,8,11,28,29}$ Our results are also in agreement with previous DFT results. ${ }^{13,14}$ Sakong and Gross found the barrier for methanol decomposition to methoxy is $0.68 \mathrm{eV}$, much lower than the barrier of $1.22 \mathrm{eV}$ for methoxy decomposition to formaldehyde. ${ }^{13}$ They also suggested that the rate-limiting step in methanol decomposition is the methoxy decomposition into formaldehyde. We also note that the barrier of the reverse process that methoxy recombines with atomic hydrogen forming methanol is $0.92 \mathrm{eV}$, which is lower than the methoxy decomposition barrier of $1.11 \mathrm{eV}$. Since the calculated barrier 


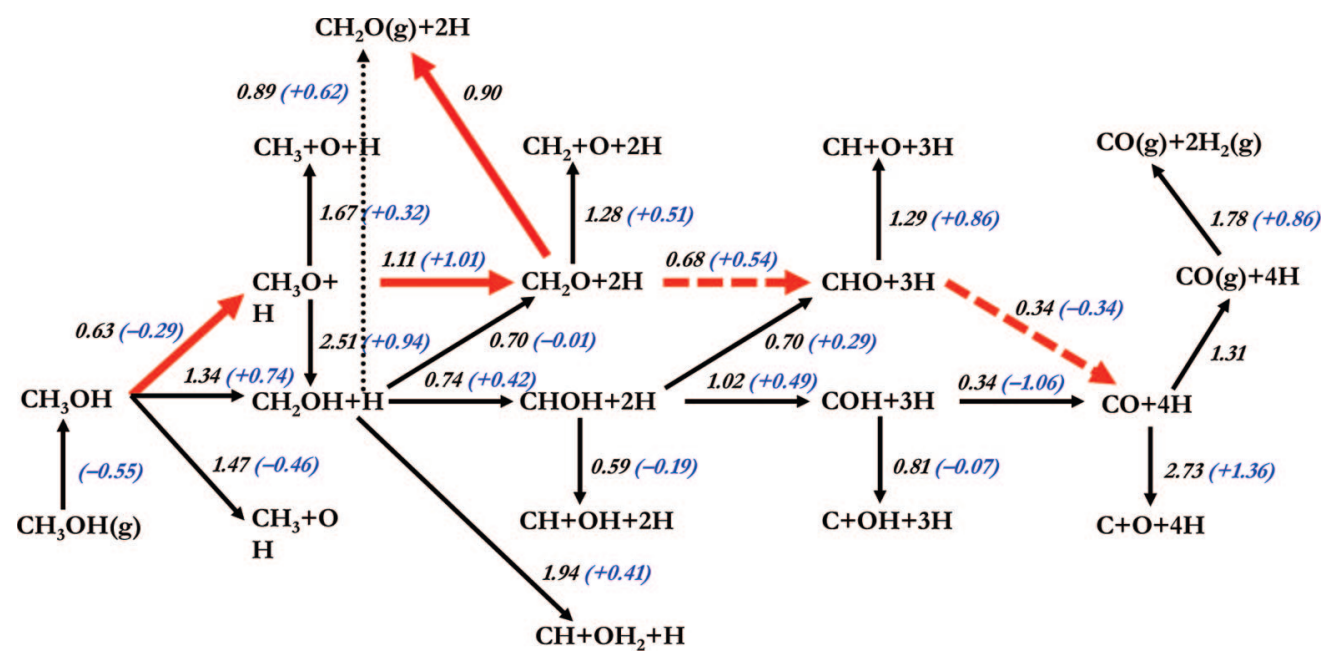

Figure 10. Reaction network of methanol decomposition on $\mathrm{Cu}(110)$. The solid and dashed lines denote all the pathways identified in the present work. The lowest activation barrier and the reaction energy (in parenthesis) of each step are listed. Any necessary diffusion barriers are assumed to be low and are not included in these energetics.

for the recombinative desorption of hydrogen is only $0.74 \mathrm{eV}$, the reverse recombination process of methoxy with hydrogen is limited by the availability of surface atomic hydrogen. As a result, methoxy can further decompose into formaldehyde with the highest barrier among entire decomposition reaction route. A further analysis of the rate constants for elementary steps that will be discussed below confirms this conclusion.

The second methanol decomposition route begins with the initial $\mathrm{C}-\mathrm{H}$ bond scission of methanol. Following the lowest barrier for each step, the second methanol decomposition route proceeds as

$$
\mathrm{CH}_{3} \mathrm{OH} \rightarrow \mathrm{CH}_{2} \mathrm{OH} \rightarrow \mathrm{CH}_{2} \mathrm{O}(\text { or } \mathrm{CHOH}) \rightarrow \mathrm{CHO} \rightarrow \mathrm{CO}
$$

Compared to the most favorable decomposition route, the first step involving methanol dissociation into hydroxymethyl is difficult. Methanol dehydrogenation into hydroxymethyl is the rate-limiting step in this second methanol decomposition route. After the formation of hydroxymethyl, two steps that lead to formaldehyde and hydroxymethylene are competitive with nearly the same activation barriers. We note that surface hydroxymethylene species is unstable because there are three subsequent low-barrier reaction paths, the most favorable being the hydrogenation back into hydroxymethyl. It is worth mentioning that, although hydroxymethyl is unlikely to be formed from methanol decomposition via $\mathrm{C}-\mathrm{H}$ bond scission, hydroxymethyl could be formed by gas-phase formaldehyde or by hydrogenation (the reverse processes of second route) since the barriers of these steps are small. As shown in Figure 10, the barriers for the reaction from formaldehyde to hydroxymethyl, hydroxymethylene hydrogenation to hydroxymethyl, as well as formyl hydrogenation to hydroxymethylene are 0.27 , 0.32 , and $0.41 \mathrm{eV}$, respectively. Therefore, it is important that the complete picture of methanol decomposition on $\mathrm{Cu}(110)$ should include the second methanol decomposition route and the corresponding surface intermediate species despite the fact that these species are not clearly identified in the experiments.

The energies listed in Figure 10 do not include zero-point energy effect corrections (ZPECs). Harmonic ZPECs were calculated for all pathways based upon vibrational frequencies of initial, transition, and the final states. It is found that ZPECs do not alter the general trend and conclusions of this work, although they do contribute a small reduction in the activation barrier for each pathway $(<0.1 \mathrm{eV})$.
Although we have focused on the decomposition reaction pathways of each intermediate via one of three possible bond scissions, several other reaction pathways that involve multiple bond-breaking and bond-making processes have also been identified. For example, we have discussed the concurrent $\mathrm{C}-\mathrm{O}$ and $\mathrm{C}-\mathrm{H}$ scissions of $\mathrm{CH}_{2} \mathrm{OH}$ forming $\mathrm{CH}$ and $\mathrm{H}_{2} \mathrm{O}$ in section 3.2.3.3. Another example is that we find a direct conversion between methoxy and hydroxymethyl. The activation barrier of this intermolecular hydrogen transfer reaction is $2.51 \mathrm{eV}$, and the reaction energy is $+0.94 \mathrm{eV}$. The direct pathway to hydrogen production from hydroxymethylidyne is also identified. The barrier for $\mathrm{CHOH} \leftrightarrow \mathrm{CO}+\mathrm{H}_{2}$ (gas) path is $2.97 \mathrm{eV}$. Since these reaction pathways are kinetically unimportant due to their extremely high barriers, we do not discuss these reaction pathways in detail.

The actual reaction rate constants of the elementary steps depend not only on the magnitude of activation barriers but also on the pre-exponential factors. The reaction rate constant $r_{i}$ of each path (both forward and reverse) is calculated using harmonic transition state theory ${ }^{30,31}$

$$
r_{i}=v_{i} \exp \left(\frac{-E_{\mathrm{a}}^{\ddagger}}{R T}\right)
$$

where $v_{i}$ is the pre-exponential factor and $E_{\mathrm{a}}^{\ddagger}$ is the activation barrier. Within harmonic transition state theory, we can calculate the pre-exponential factors $\left(v_{i}\right)$ of each reaction pathway using

$$
v_{i}=\frac{\prod_{1}^{3 N} f_{i}^{\mathrm{IS}}}{\prod_{1}^{3 N-1} f_{i}^{\mathrm{TS}}}
$$

the following definition:

where $f_{i}^{\mathrm{IS}}$ are the vibrational frequencies at the initial state and $f_{i}^{\mathrm{TS}}$ are the vibrational frequencies at the transition (excluding the imaginary one). For the reverse pathway, the $f_{i}^{\mathrm{FS}}$, which are the vibrational frequencies at the final state, were used instead of $f_{i}^{\mathrm{IS}}$ in eq 3 . All calculated pre-exponential factors along with the reaction rate constants for the identified pathways at $300 \mathrm{~K}$ are listed in Table 3. 


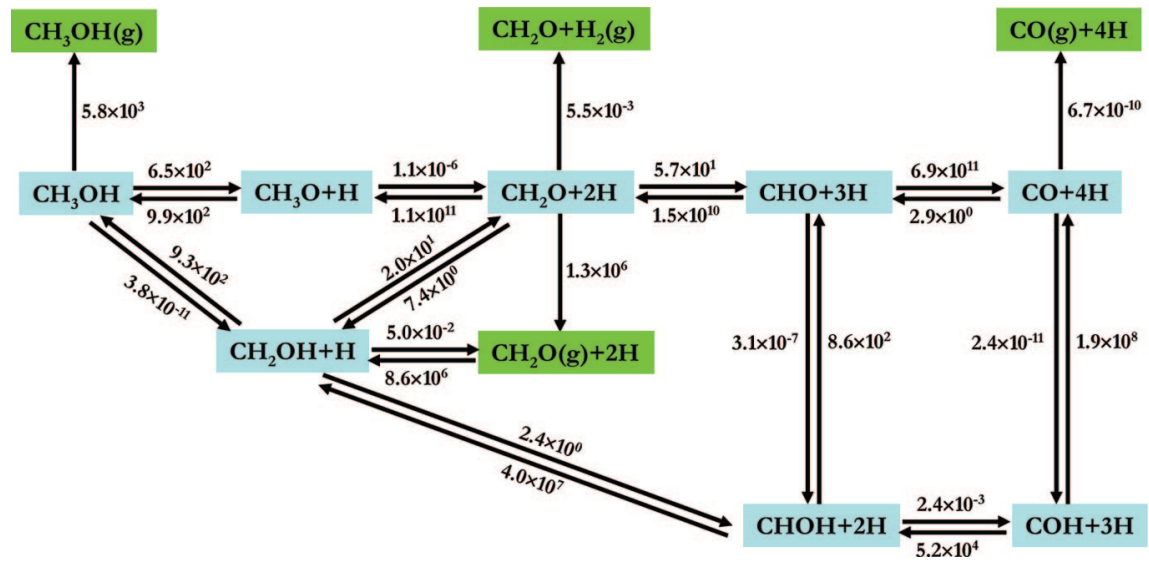

Figure 11. Calculated reaction rate constants for the major elementary steps in methanol decomposition on $\mathrm{Cu}(110)$.

TABLE 3: Calculated Activation Barriers $E^{\ddagger}(\mathrm{eV})$, the Pre-exponential Factors $v\left(\mathrm{~s}^{-1}\right)$, and the Rate Constants $k\left(\mathrm{~s}^{-1}\right)$ at $300 \mathrm{~K}$ for the Identified Reaction and Diffusion Pathways ${ }^{a}$

\begin{tabular}{|c|c|c|c|c|c|c|}
\hline reaction paths & $v_{\text {forward }}$ & $E_{\text {forward }}^{ \pm}$ & $v_{\text {reverse }}$ & $E_{\text {reverse }}^{\neq}$ & $k_{\text {forward }}$ & $k_{\text {reverse }}$ \\
\hline $\mathrm{CH}_{3} \mathrm{O}^{*} \mathrm{H}(\mathrm{sb}) \leftrightarrow \mathrm{CH}_{3} \mathrm{O}^{*}(\mathrm{sb})+\mathrm{H}(\mathrm{sb})$ & $2.38 \times 10^{13}$ & 0.63 & $2.84 \times 10^{12}$ & 0.92 & $6.46 \times 10^{2}$ & $9.20 \times 10^{-4}$ \\
\hline $\mathrm{CH}_{3} \mathrm{O} * \mathrm{H}($ top $) \leftrightarrow \mathrm{CH}_{3} \mathrm{O} *($ top $)+\mathrm{H}(\mathrm{sb})$ & $1.17 \times 10^{12}$ & 0.86 & $2.03 \times 10^{13}$ & 0.53 & $7.22 \times 10^{-2}$ & $9.90 \times 10^{2}$ \\
\hline $\mathrm{CH}_{3} \mathrm{O} * \mathrm{H}($ top $) \leftrightarrow \mathrm{CH}_{3} \mathrm{O} *(\mathrm{sb})+\mathrm{H}(\mathrm{fcc})$ & $1.19 \times 10^{12}$ & 1.10 & $5.07 \times 10^{13}$ & 1.28 & $4.44 \times 10^{-7}$ & $1.53 \times 10^{-8}$ \\
\hline $\mathrm{CH}_{3} \mathrm{O} * \mathrm{H}($ top $) \leftrightarrow \mathrm{C}^{*} \mathrm{H}_{2} \mathrm{OH}(\mathrm{sb})+\mathrm{H}(\mathrm{sb})$ & $1.40 \times 10^{12}$ & 1.34 & $1.47 \times 10^{13}$ & 0.61 & $3.82 \times 10^{-11}$ & $9.34 \times 10^{2}$ \\
\hline $\mathrm{CH}_{3} \mathrm{O} * \mathrm{H}$ (top) $\leftrightarrow \mathrm{C}^{*} \mathrm{H}_{3}(\mathrm{sb})+\mathrm{O} * \mathrm{H}(\mathrm{fcc})$ & $4.87 \times 10^{13}$ & 1.47 & $1.08 \times 10^{14}$ & 1.94 & $9.43 \times 10^{-12}$ & $3.22 \times 10^{-19}$ \\
\hline $\mathrm{CH}_{3} \mathrm{O} * \mathrm{H}($ top $) \leftrightarrow \mathrm{C}^{*} \mathrm{H}_{3}(\mathrm{sb})+\mathrm{O} * \mathrm{H}(\mathrm{sb})$ & $1.47 \times 10^{12}$ & 1.74 & $1.72 \times 10^{13}$ & 2.38 & $1.05 \times 10^{-17}$ & $1.79 \times 10^{-27}$ \\
\hline $\mathrm{CH}_{3} \mathrm{O} *(\mathrm{sb}) \leftrightarrow \mathrm{C}^{*} \mathrm{H}_{3}(\mathrm{sb})+\mathrm{O}(\mathrm{fcc})$ & $1.09 \times 10^{13}$ & 2.10 & $3.93 \times 10^{13}$ & 1.85 & $5.49 \times 10^{-23}$ & $3.96 \times 10^{-18}$ \\
\hline $\mathrm{C}^{*} \mathrm{H}_{2} \mathrm{O}^{*} \mathrm{H}(\mathrm{sb}) \leftrightarrow \mathrm{C}^{*} \mathrm{H}_{2} \mathrm{O} *(\mathrm{sb})+\mathrm{H}(\mathrm{fcc})$ & $1.03 \times 10^{12}$ & 0.70 & $5.79 \times 10^{12}$ & 0.71 & $2.02 \times 10^{1}$ & $7.38 \times 10^{0}$ \\
\hline $\mathrm{C}^{*} \mathrm{H}_{2} \mathrm{OH}(\mathrm{sb}) \leftrightarrow \mathrm{C}^{*} \mathrm{HOH}(\mathrm{sb})+\mathrm{H}(\mathrm{sb})$ & $5.61 \times 10^{12}$ & 0.74 & $8.38 \times 10^{12}$ & 0.32 & $2.42 \times 10^{0}$ & $3.96 \times 10^{7}$ \\
\hline $\mathrm{C}^{*} \mathrm{H}_{2} \mathrm{O} * \mathrm{H}(\mathrm{lb}) \leftrightarrow \mathrm{C}^{*} \mathrm{H}_{2} \mathrm{O} *(\mathrm{lb})+\mathrm{H}(\mathrm{fcc})$ & $4.14 \times 10^{13}$ & 0.84 & $4.05 \times 10^{13}$ & 0.86 & $3.88 \times 10^{-1}$ & $1.24 \times 10^{-1}$ \\
\hline $\mathrm{C}^{*} \mathrm{H}_{2} \mathrm{OH}(\mathrm{sb}) \leftrightarrow \mathrm{CH}_{2} \mathrm{O}($ gas $)+\mathrm{H}(\mathrm{fcc})$ & $3.81 \times 10^{13}$ & 0.89 & $2.96 \times 10^{11}$ & 0.27 & $4.96 \times 10^{-2}$ & $8.61 \times 10^{6}$ \\
\hline $\mathrm{C}^{*} \mathrm{H}_{2} \mathrm{O} * \mathrm{H}(\mathrm{sb}) \leftrightarrow \mathrm{C}^{*} \mathrm{H}_{2} \mathrm{O} *(\mathrm{sb})+\mathrm{H}(\mathrm{fcc})$ & $1.75 \times 10^{14}$ & 1.19 & $6.05 \times 10^{13}$ & 1.03 & $1.53 \times 10^{-6}$ & $3.24 \times 10^{-4}$ \\
\hline $\mathrm{C}^{*} \mathrm{H}_{2} \mathrm{O} *(\mathrm{lb}) \leftrightarrow \mathrm{C}^{*} \mathrm{H}_{2}(\mathrm{lb})+\mathrm{O}(\mathrm{fcc})$ & $2.41 \times 10^{13}$ & 1.82 & $2.09 \times 10^{13}$ & 1.46 & $5.92 \times 10^{-18}$ & $5.51 \times 10^{-12}$ \\
\hline $\mathrm{C}^{*} \mathrm{H}_{2} \mathrm{O} *(\mathrm{sb}) \leftrightarrow \mathrm{C} * \mathrm{H}_{2} \mathrm{O} *(\mathrm{lb})$ & $2.02 \times 10^{12}$ & 0.47 & $1.00 \times 10^{13}$ & 0.62 & $2.38 \times 10^{4}$ & $3.42 \times 10^{2}$ \\
\hline $\mathrm{C}^{*} \mathrm{HO} * \mathrm{H}(\mathrm{lb}) \leftrightarrow \mathrm{C} * \mathrm{H}(\mathrm{lb})+\mathrm{O} * \mathrm{H}(\mathrm{sb})$ & $5.03 \times 10^{12}$ & 0.44 & $1.69 \times 10^{13}$ & 0.90 & $1.89 \times 10^{5}$ & $1.38 \times 10^{-2}$ \\
\hline $\mathrm{C} * \mathrm{HOH}(\mathrm{sb}) \leftrightarrow \mathrm{C}^{*} \mathrm{H}(\mathrm{fcc})+\mathrm{O} * \mathrm{H}(\mathrm{sb})$ & $6.92 \times 10^{10}$ & 0.59 & $8.55 \times 10^{13}$ & 0.78 & $8.47 \times 10^{0}$ & $7.85 \times 10^{0}$ \\
\hline $\mathrm{C} * \mathrm{HO} * \mathrm{H}(\mathrm{lb}) \leftrightarrow \mathrm{C} * \mathrm{HO}(\mathrm{sb})+\mathrm{H}(\mathrm{sb})$ & $5.99 \times 10^{12}$ & 0.59 & $1.40 \times 10^{13}$ & 1.17 & $8.56 \times 10^{2}$ & $3.09 \times 10^{-7}$ \\
\hline $\mathrm{C}^{*} \mathrm{HOH}(\mathrm{sb}) \leftrightarrow \mathrm{C}^{*} \mathrm{HO}(\mathrm{sb})+\mathrm{H}(\mathrm{fcc})$ & $8.55 \times 10^{13}$ & 0.70 & $6.92 \times 10^{10}$ & 0.41 & $1.73 \times 10^{2}$ & $8.95 \times 10^{3}$ \\
\hline $\mathrm{C}^{*} \mathrm{HOH}(\mathrm{top}) \leftrightarrow \mathrm{C}^{*} \mathrm{HO}(\mathrm{sb})+\mathrm{H}(\mathrm{fcc})$ & $1.26 \times 10^{13}$ & 0.92 & $1.34 \times 10^{13}$ & 0.57 & $4.24 \times 10^{-3}$ & $3.05 \times 10^{3}$ \\
\hline $\mathrm{C} * \mathrm{HOH}(\mathrm{sb}) \leftrightarrow \mathrm{C} * \mathrm{H}(\mathrm{fcc})+\mathrm{O} * \mathrm{H}(\mathrm{sb})$ & $2.45 \times 10^{13}$ & 0.92 & $6.70 \times 10^{14}$ & 0.57 & $8.25 \times 10^{-3}$ & $1.52 \times 10^{5}$ \\
\hline $\mathrm{C} * \mathrm{HOH}(\mathrm{sb}) \leftrightarrow \mathrm{C} * \mathrm{H}(\mathrm{fcc})+\mathrm{O} * \mathrm{H}(\mathrm{sb})$ & $3.57 \times 10^{12}$ & 0.97 & $7.65 \times 10^{12}$ & 1.14 & $1.74 \times 10^{-4}$ & $5.39 \times 10^{-7}$ \\
\hline $\mathrm{C} * \mathrm{HOH}(\mathrm{sb}) \leftrightarrow \mathrm{C} * \mathrm{OH}(\mathrm{fcc})+\mathrm{H}(\mathrm{fcc})$ & $3.20 \times 10^{13}$ & 1.02 & $4.89 \times 10^{13}$ & 0.53 & $2.43 \times 10^{-4}$ & $5.22 \times 10^{4}$ \\
\hline $\mathrm{C} * \mathrm{HOH}(\mathrm{sb}) \leftrightarrow \mathrm{C}^{*} \mathrm{OH}(\mathrm{fcc})+\mathrm{H}(\mathrm{fcc})$ & $3.68 \times 10^{13}$ & 1.14 & $1.92 \times 10^{13}$ & 0.12 & $2.80 \times 10^{-6}$ & $1.78 \times 10^{11}$ \\
\hline $\mathrm{C} * \mathrm{HOH}(\mathrm{sb}) \leftrightarrow \mathrm{C}^{*} \mathrm{OH}(\mathrm{fcc})+\mathrm{H}(\mathrm{sb})$ & $7.85 \times 10^{13}$ & 1.36 & $2.55 \times 10^{13}$ & 0.72 & $1.03 \times 10^{-9}$ & $2.39 \times 10^{1}$ \\
\hline
\end{tabular}

${ }^{a} \mathrm{sb}, \mathrm{lb}$, and fcc denote the short-bridge, the long-bridge, and pseudo-fcc(111) sites, respectively.

Figure 11 illustrates the important elementary steps in methanol decomposition on $\mathrm{Cu}(110)$. The rate constant of each step listed in Figure 11 is calculated using the pathway with the lowest barrier. Because the diffusion barriers of reaction intermediates are generally small, we assume that the migration of each reaction intermediate from the most stable state to the initial state in the decomposition (or its reverse recombination process) step will not affect the progress of the entire decomposition reaction. The first step for methanol decomposition is methanol dissociates into methoxy via $\mathrm{O}-\mathrm{H}$ bond scission. Our calculated rate constant for this step is $6.5 \times 10^{2} \mathrm{~s}^{-1}$, which is slower than the desorption rate constant of $5.8 \times 10^{3} \mathrm{~s}^{-1}$ for adsorbed methanol. The adsorbed methanol would rather desorb from the surface than dissociate into methoxy on the clean $\mathrm{Cu}(110)$ surface. This is consistent to the experimental TPD results that most adsorbed methanol desorb from the surface with the peak temperature below $200 \mathrm{~K}$ and only a small amount of methanol dissociated into methoxy on the clean $\mathrm{Cu}(110)$ surface. ${ }^{7,8,11}$ The calculated rate constants suggest that the $\mathrm{O}-\mathrm{H}$ bond scission of methanol is a quasi-equilibrium step since the 
forward and the reverse rate constants are very close $(6.5 \times$ $10^{2} \mathrm{~s}^{-1}$ vs $9.9 \times 10^{2} \mathrm{~s}^{-1}$ ).

The rate-limiting step for methanol decomposition on $\mathrm{Cu}(110)$ is the abstraction of a methylic hydrogen ( $\mathrm{C}-\mathrm{H}$ bond scission) of methoxy to produce formaldehyde. The calculated preexponential factor and the activation barrier are $5.5 \times 10^{12} \mathrm{~s}^{-1}$ and $1.11 \mathrm{eV}$, respectively. Madix and Telfold studied the primary and second kinetic effects of methoxy dehydrogenation on $\mathrm{Cu}(110){ }^{29}$ The pre-exponential factor of $0.8 \pm 0.3 \times 10^{12}$ $\mathrm{s}^{-1}$ and the activation energy of $0.91 \mathrm{eV}$ have been reported based on a first-order reaction assumption. Our calculated activation barrier is slightly higher than the experimentally measured barrier, but the pre-exponential factor is also somewhat larger. As a result, our calculated reaction rate constant of 1.1 $\times 10^{-6} \mathrm{~s}^{-1}$ for methoxy decomposition to formaldehyde is slightly lower than the experimentally measured rate of $4.1 \times$ $10^{-4} \mathrm{~s}^{-1} .{ }^{29}$ The formed methoxy can recombine with a neighboring atomic $\mathrm{H}$ to yield methanol. Our calculated rate constant for this process is $9.9 \times 10^{2} \mathrm{~s}^{-1}$, which is significantly faster than methoxy decomposition to formaldehyde. However, since the recombinative desorption of hydrogen on $\mathrm{Cu}(110)$ is faster, the methoxy recombining with the atomic hydrogen forming methanol is limited by the availability of surface atomic hydrogen. This causes the methoxy decomposition step to be even more difficult on the $\mathrm{Cu}(110)$ surface. It is well-known that the preadsorbed atomic $\mathrm{O}$ on this surface facilitates methanol decomposition. ${ }^{7,8,11}$ Surface oxygen atoms not only promote methanol decomposition by directly reacting with incoming gas-phase methanol but also prevent the formation of methanol from the recombination of methoxy and hydrogen by removing surface hydrogen to form water. Previous DFT calculations show that the rate-limiting step is very slightly affected by the presence of surface $\mathrm{O}$ atoms. The barrier for methoxy decomposition to formaldehyde is lowered by only $0.14 \mathrm{eV}$ with the assistance of surface oxygen. ${ }^{14}$

Once formaldehyde is formed on $\mathrm{Cu}(110)$, it can be consumed through four possible reaction pathways. Formaldehyde can easily desorb from the surface or be hydrogenated into methoxy or hydroxymethyl by recombining with hydrogen or dehydrogenated into formyl via $\mathrm{C}-\mathrm{H}$ bond scission. The hydrogenation of formaldehyde to methoxy is $10^{5}$ times faster than formaldehyde desorption and will dominate if sufficient atomic hydrogen is available. Our results are consistent with the experimental observations that methoxy is the most abundant and stable species in methanol decomposition on the $\mathrm{Cu}(110)$ surface. ${ }^{7,8,11}$ Sexton et al. found methoxy is stable until $360-370 \mathrm{~K} .{ }^{11}$ The other two reaction paths for formaldehyde dehydrogenation to formyl or formaldehyde hydrogenation to hydroxymethyl are slower. As shown in Figure 11, the most favorable route of $\mathrm{CH}_{3} \mathrm{OH} \rightarrow \mathrm{CH}_{3} \mathrm{O} \rightarrow \mathrm{CH}_{2} \mathrm{O} \rightarrow \mathrm{CHO} \rightarrow \mathrm{CO}$, has the dehydrogenation of formaldehyde to formyl as the second slowest step. Even though the step for formyl decomposing into $\mathrm{CO}$ is very fast $\left(4.1 \times 10^{-4} \mathrm{~s}^{-1}\right)$, the second bottleneck step that formyl produced from the dehydrogenation of formaldehyde is slow. As such, the $\mathrm{CO}$ formation is hindered. Formaldehyde becomes the final product for methanol decomposition on $\mathrm{Cu}(110)$. Wachs and Madix studied formaldehyde oxidation on $\mathrm{Cu}(110)$ surface. They claimed that almost all formaldehyde molecularly adsorbs on the surface and the $\mathrm{Cu}(110)$ surface cannot break the $\mathrm{C}-\mathrm{H}$ bond to produce formyl. ${ }^{27}$ This is the reason why $\mathrm{CO}$ is not identified in methanol decomposition experiments on the clean $\mathrm{Cu}(110)$ surface. $^{27}$

We have found that gas-phase formaldehyde reacts with surface hydrogen atom, forming hydroxymethyl species on
$\mathrm{Cu}(110)$. The rate constant of this step is high $\left(8.6 \times 10^{6} \mathrm{~s}^{-1}\right)$. Once hydroxymethyl is formed, it is most likely hydrogenated into methanol if adjacent surface atomic hydrogen is available. Except for the favorable hydrogenation path, hydroxymethyl can be dehydrogenated into formaldehyde via $\mathrm{O}-\mathrm{H}$ bond scission and either release formaldehyde into the gas phase or remain adsorbed to the surface. Based on calculated rate constants, the reaction pathway leading to the adsorbed formaldehyde $\left(2.0 \times 10^{1} \mathrm{~s}^{-1}\right)$ is preferred to the release of formaldehyde in the gas phase $\left(5.0 \times 10^{-2} \mathrm{~s}^{-1}\right)$. However, since there is a strong repulsive interaction between coadsorbed formaldehyde and atomic hydrogen, formaldehyde might quickly desorb after the reaction. Hydroxymethyl can also be dehydrogenated into hydroxymethylene via $\mathrm{C}-\mathrm{H}$ bond scission. However, all above three reaction paths are relatively slow. As a result, neither hydroxymethyl nor hydroxymethylene had been detected on $\mathrm{Cu}(110)$ in methanol TPD experiments.

\section{Conclusions}

The potential energy surface of methanol on the $\mathrm{Cu}(110)$ has been explored using periodic DFT calculations combined with the dimer saddle point searching method. Starting from the initial state that stable adsorbed methanol at the short-bridge site on $\mathrm{Cu}(110)$, we have identified multiple reaction pathways for each possible bond $(\mathrm{O}-\mathrm{H}, \mathrm{C}-\mathrm{H}$, and $\mathrm{C}-\mathrm{O})$ scission process in methanol decomposition. We also calculated the pre-exponential factor of each identified reaction and obtained the reaction rate constant of each identified reaction pathway in the reaction network using harmonic transition state theory. On the basis of calculated rate constants, we found that $\mathrm{CH}_{3} \mathrm{OH} \rightarrow \mathrm{CH}_{3} \mathrm{O} \rightarrow$ $\mathrm{CH}_{2} \mathrm{O} \rightarrow \mathrm{CHO} \rightarrow \mathrm{CO}$ is the most favorable route for methanol complete decomposition toward $\mathrm{CO}$ on $\mathrm{Cu}(110)$. In this complete decomposition route, the formed formaldehyde most likely desorbs from the surface before further dehydrogenation into $\mathrm{CO}$. The rate-limiting step in this route is the dehydrogenation of methoxy to formaldehyde. Our calculations are in agreement with the reported experimental data and observations, and most importantly, we demonstrated that the computational methodology used in this work provides a powerful tool to investigate complex heterogeneous catalytic reaction mechanisms.

Acknowledgment. This work was supported by a Laboratory Directed Research and Development (LDRD) project (F74641) of the Pacific Northwest National Laboratory (PNNL). The computations were performed using the Molecular Science Computing Facility in the William R. Wiley Environmental Molecular Sciences Laboratory (EMSL), which is a U.S. Department of Energy national scientific user facility located at PNNL in Richland, WA. Computing time was made available through a Computational Grand Challenge "Computational Catalysis", and user facility allocation EMSL-25428. Part of the computing time was also granted by the National Energy Research Scientific Computing Center (NERSC). G.H. gratefully acknowledges support from the NSF CAREER program (CHE0645497), the Norman Hackerman Advanced Research Program, and the Welch Foundation (F-1601).

\section{References and Notes}

(1) Henkelman, G.; Jonsson, H. J. Chem. Phys. 1999, 111, 7010.

(2) Mei, D.; Xu, L.; Henkelman, G. J. Catal. 2008, 258, 44.

(3) Olsen, R. A.; Kroes, G. J.; Henkelman, G.; Arnaldsson, A.; Jonsson, H. J. Chem. Phys. 2004, 121, 9776.

(4) Xu, L. J.; Henkelman, G. J. Chem. Phys. 2008, 129, 114104. 3992 .
(5) Palo, D. R.; Dagle, R. A.; Holladay, J. D. Chem. Rev. 2007, 107, 
(6) Rozovskii, A. Y.; Lin, G. I. Top. Catal. 2003, 22, 137.

(7) Wachs, I. E.; Madix, R. J. J. Catal. 1978, 53, 208.

(8) Bowker, M.; Madix, R. J. Surf. Sci. 1980, 95, 190.

(9) Russell, J. N.; Gates, S. M.; Yates, J. T. Surf. Sci. 1985, 163, 516.

(10) Sexton, B. A. Surf. Sci. 1979, 88, 299.

(11) Sexton, B. A.; Hughes, A. E.; Avery, N. R. Surf. Sci. 1985, 155, 366.

(12) Sakong, S.; Gross, A. J. Catal. 2005, 231, 420.

(13) Sakong, S.; Gross, A. J. Phys. Chem. A 2007, 111, 8814.

(14) Sakong, S.; Sendner, C.; Gross, A. J. Mol. Struct.: THEOCHEM 2006, 771,117 .

(15) Greeley, J.; Mavrikakis, M. J. Catal. 2002, 208, 291.

(16) Blochl, P. E. Phys. Rev. B 1994, 50, 17953.

(17) Kresse, G.; Joubert, D. Phys. Rev. B 1999, 59, 1758.

(18) Perdew, J. P.; Wang, Y. Phys. Rev. B 1992, 45, 13244.

(19) Kresse, G.; Furthmuller, J. Phys. Rev. B 1996, 54, 11169.

(20) Kresse, G.; Furthmuller, J. Comput. Mater. Sci. 1996, 6, 15.
(21) Bader, M.; Puschmann, A.; Haase, J. Phys. Rev. B 1986, 33, 7336.

(22) Desai, S. K.; Neurock, M.; Kourtakis, K. J. Phys. Chem. B 2002, $106,2559$.

(23) Greeley, J.; Mavrikakis, M. J. Am. Chem. Soc. 2002, 124, 7193.

(24) Greeley, J.; Mavrikakis, M. J. Am. Chem. Soc. 2004, 126, 3910.

(25) Janik, M. J.; Taylor, C. D.; Neurock, M. Top. Catal. 2007, 46, 306.

(26) Gomes, J. R. B.; Gomes, J. J. Electroanal. Chem. 2000, 483, 180.

(27) Wachs, I. E.; Madix, R. J. Surf. Sci. 1979, 84, 375.

(28) Barnes, C.; Pudney, P.; Guo, Q. M.; Bowker, M. J. Chem. Soc., Faraday Trans. 1990, 86, 2693.

(29) Madix, R. J.; Telford, S. G. Surf. Sci. 1995, 328, L576.

(30) Vineyard, G. H. J. Phys. Chem. Solids 1957, 3, 121.

(31) Wert, C.; Zener, C. Phys. Rev. 1949, 76, 1169.

JP808211Q 